\title{
Mushroom extracts and compounds with suppressive action on breast cancer: evidence from studies using cultured cancer cells, tumor-bearing animals, and clinical trials
}

Jack Ho Wong, Tzi Bun Ng, Helen Hei Ling Chan, Qin Liu, Gene Chi Wai Man, Chris Zhiyi Zhang, Suzhen Guan, Charlene Cheuk Wing Ng, Evandro Fei Fang, Hexiang Wang, Fang Liu, Xiuyun Ye, Krzysztof Rolka, Ryno Naude, Shuang Zhao, Ou Sha, Chunman Li \& Lixin Xia

Affiliations

1. State Key Laboratory of Respiratory Disease for Allergy, School of Medicine, Shenzhen University, Shenzhen, Guangdong, China

Jack Ho Wong, Ou Sha, Chunman Li \& Lixin Xia

2. School of Biomedical Sciences, Faculty of Medicine, The Chinese University of Hong Kong, Hong Kong, China

Tzi Bun $\mathrm{Ng}$

3. The Chinese University of Hong Kong (CUHK) Shenzhen Research Institute, Shenzhen, China

Tzi Bun $\mathrm{Ng}$

4. Vita Green Pharmaceuticals (Hong Kong) Limited, Hong Kong, China

Helen Hei Ling Chan

5. Institute of Plant Nutrition, Agricultural Resources and Environmental Science, Henan Academy of Agricultural Sciences, Zhengzhou, China

Qin Liu

6. Department of Orthopedics and Traumatology, The Chinese University of Hong Kong, Hong Kong, China

Gene Chi Wai Man

7. State Key Laboratory of Oncology in Southern China, Sun Yat-Sen University Cancer Center and Department of Pathology, Sun Yat-Sen University Cancer Center, Guangzhou, China

Chris Zhiyi Zhang

8. Department of Social Medicine, College of Public Health, Xinjiang Medical University, Urumqi, China

Suzhen Guan

9. School of Medicine, King's College London, London, UK

Charlene Cheuk Wing Ng

10. Department of Clinical Molecular Biology, University of Oslo and Akershus University Hospital, Lørenskog, Norway

Evandro Fei Fang

11. The Norwegian Centre on Healthy Ageing (NO-Age), Oslo, Norway 


\section{Evandro Fei Fang}

12. Department of Microbiology, China Agricultural University, Beijing, China

Hexiang Wang

13. Department of Microbiology, The Key Laboratory of Molecular Microbiology and Technology, Ministry of Education, Nankai University, Tianjin, China

\section{Fang Liu}

14. Fujian Key Laboratory of Marine Enzyme Engineering, Fuzhou University, Fuzhou, Fujian, China

Xiuyun Ye

15. Department of Molecular Biochemistry, Faculty of Chemistry, University of Gdańsk, Wita Stwosza 63, Gdańsk, Poland

Krzysztof Rolka

16. Department of Biochemistry and Microbiology, Nelson Mandela University, Port Elizabeth, 6031, South Africa

Ryno Naude

17. Key Laboratory of Vegetable Postharvest Processing, Institute of Plant and Environment Protection, Beijing Academy of Agriculture and Forestry Sciences, and Beijing Key Laboratory of Fruits and Vegetable Storage and Processing, Ministry of Agriculture, Beijing, China

Shuang Zhao

Corresponding authors: Correspondence to Jack Ho Wong or Tzi Bun Ng or Helen Hei Ling Chan or Chunman Li or Lixin Xia. 


\begin{abstract}
This article reviews mushrooms with anti-breast cancer activity. The mushrooms covered which are better known include the following: button mushroom Agaricus bisporus, Brazilian mushroom Agaricus blazei, Amauroderma rugosum, stout camphor fungus Antrodia camphorata, Jew's ear (black) fungus or black wood ear fungus Auricularia auricula-judae, reishi mushroom or Lingzhi Ganoderma lucidum, Ganoderma sinense, maitake mushroom or sheep's head mushroom Grifola frondosa, lion's mane mushroom or monkey head mushroom Hericium erinaceum, brown beech mushroom Hypsizigus marmoreus, sulfur polypore mushroom Laetiporus sulphureus, Lentinula edodes (shiitake mushroom), Phellinus linteus (Japanese "meshimakobu," Chinese "song gen," Korean "sanghwang," American "black hoof mushroom"), abalone mushroom Pleurotus abalonus, king oyster mushroom Pleurotus eryngii, oyster mushroom Pleurotus ostreatus, tuckahoe or Fu Ling Poria cocos, and split gill mushroom Schizophyllum commune. Antineoplastic effectiveness in human clinical trials and mechanism of anticancer action have been reported for Antrodia camphorata, Cordyceps sinensis, Coriolus versicolor, Ganoderma lucidum, Grifola frondosa, and Lentinula edodes.
\end{abstract}




\section{Introduction}

Since mushrooms are nutritious and delicious, very often they form popular dietary components. Mushrooms are abundant in protein, fiber, B vitamins, vitamin D, antioxidants, potassium, and selenium. There are medicinal as well as culinary-medicinal mushrooms. Some species are renowned worldwide, for instance, shiitake mushroom (Lentinula edodes), maitake mushroom (Grifola frondosa), button mushroom (Agaricus bisporus), Brazilian mushroom (Agaricus brasiliensis), Jew's ear fungus (Auricularia auricularis), oyster mushroom (Pleurotus oztreatus), turkey tail mushroom or Yunzhi (Coriolus versicolor), caterpillar fungus (Cordyceps militaris and Cordyceps sinensis), and reishi mushroom/Lingzhi (Ganoderma species). Mushrooms manifest an impressive array of health-promoting activities including anticancer, immunostimulating, antihyperglycemic, antihypertensive, neuroprotective, hepatoprotective, antifungal, antibacterial, prebiotic, and antiviral activities. Various mushroom species including Agaricus, Albatrellus, Antrodia, Calvatia, Clitocybe, Cordyceps, Flammulina, Fomes, Funlia, Ganoderma, Inocybe, Inonotus, Lactarius, Phellinus, Pleurotus, Russula, Schizophyllum, Suillus, Trametes, and Xerocomus produce compounds with inhibitory activity on cancers. These compounds exhibit their anticancer effects through their actions as angiogenesis inhibitors, antimitotic agents, mitotic kinase inhibitors, reactive oxygen species inducers, and topoisomerase inhibitors (Patel and Goyal 2012). Different mushroom tissues such as fruiting body and mycelium and different constituents such as glucans and proteins can display antitumor activity. For instance, polysaccharides derived from the fruiting body extracts as well as mycelial extracts of Pleurotus pulmonarius inhibited proliferation and adhesion and triggered apoptosis of colorectal cancer cells (Lavi et al. 2006, 2010). The extracts (Lavi et al. 2012) and the derived glucans (Schwartz and Hadar 2014) suppressed colon cancer associated with colitis in mice. Ostreolysin from Pleurotus ostreatus and its recombinant form reduced the viability of colon cancer cells in tumor-bearing mice (Nimri et al. 2017). Mushrooms have anticancer activity toward different cancers. Besides colon cancer referred to above, many mushrooms have a repressive effect on breast cancer which affects innumerable women worldwide. Inclusion of mushrooms in the diet is protective against cancer (Dunneram et al. 2019). Since breast cancer was the most commonly diagnosed cancer and the leading cause of cancer death in females in 2018 (Bray et al. 2018), the purpose of the present review is to review the various mushroom species with a reportedly inhibitory action on breast cancer which is a devastating disease.

\section{Agaricus bisporus}

White button mushroom (Agaricus bisporus) extract and its ingredient conjugated linoleic acid inhibited testosterone-induced cell proliferation in MCF-7aro breast cancer cells but were devoid of activity toward nontumorigenic MCF-10A cells. The extract suppressed tumor growth in nude mice bearing MCF-7aro xenografts (Chen et al. 2006). A lectin-like mannose-binding protein (orf239342) from A. bisporus was associated with mushroom tyrosinase and exerted mannose-inhibitable antiproliferative activity on MCF-7 breast cancer cells (Rachmawati et al. 2019).

Agaricus blazei (also known as Agaricus brasiliensis)

Brefeldin $\quad \mathrm{A}[(1 \mathrm{R}, 2 \mathrm{E}, 6 \mathrm{~S}, 10 \mathrm{E}, 11 \mathrm{aS}, 13 \mathrm{~S}, 14 \mathrm{aR})$-1,13-dihydroxy-6-methyl-1,6,7,8,9,11a, 12,13,14,14a-decahydro-4H-cyclopenta[f]oxacyclotridecin-4-one], an estrogenic Erk1/2activating compound devoid of growth-stimulating activity in breast cancer MCF-7 cells has been isolated from Agaricus blazei mycelia. It may have applications as functional foods and therapeutics (Dong et al. 2013).

Agaricus placomyces 
The 68-kDa laccase from Agaricus placomyces belongs to a family of copper-containing oxidases involved in lignin degradation and possessing anticancer activity (Mizerska-Dudka et al. 2015). It potently expressed antiproliferative activity toward MCF-7 human breast cancer cells with an IC50 of $1.8 \mu \mathrm{M}$ (Sun et al. 2012).

\section{Agaricus sylvaticus}

In a randomized, double-blind, and placebo-controlled clinical trial, 46 patients with stage II and III breast cancer who received chemotherapy demonstrated an improved appetite and fewer gastrointestinal complaints, nausea, and vomiting following dietary supplementation with A. sylvaticus (2.1 g/day) (Valadares et al. 2013).

\section{Amauroderma rude}

Amauroderma rude had higher tumoricidal activity than Ganoderma lucidum. A. rude lowered cell survival and triggered apoptosis in MDA-MB-231 breast cancer cells. Tumor growth in athymic nude mice bearing MDA-MB-231-xenografts was retarded and tumor cell death was promoted by treatment with $A$. rude. Expression of the c-Myc oncogene was downregulated (Jiao et al. 2013). A. rude exhibited a higher content of ergosterol (ergosta-5,7,22-trien-3 $\beta$-ol) in comparison with 12 other mushrooms examined. Under the influence of ergosterol, the viability of MDA-MB-231 breast cancer cells was reduced, whereas expression of the tumor suppressor Foxo3 and downstream signaling molecules including BimL, BimS, Fas, and FasL was enhanced resulting in apoptosis of the breast cancer cells (Li et al. 2015).

\section{Amauroderma rugosum (also known as black Lingzhi, a member of five-color Lingzhi)}

Organic molecules from $A$. rugosum inhibited oxidant activity, tumor necrosis factor- $\alpha$ and nitric oxide formation, and MCF7 cell proliferation (Zhang et al. 2017a). A single treatment with pulverized A. rugosum ( $2000 \mathrm{mg} / \mathrm{kg}$ ) by mouth did not impair growth, blood parameters, histological structures of the organs examined, or survival of the rats in the study period of 2 weeks (Fung et al. 2017).

\section{Antrodia camphorata/Antrodia cinnamomea}

This mushroom exhibited inhibitory activity against a host of cancers including breast, bladder, cervical, colorectal, glioblastoma, leukemia, liver, lung, lymphoma, melanoma, neuroblastoma, ovarian, pancreatic, and prostate cancers (Wang et al. 2019). In response to a fermented culture broth of $A$. camphorata, various parameters encompassing expression of matrix metalloproteinase-2, matrix metalloproteinase-9, urokinase plasminogen activator, urokinase plasminogen activator receptor and vascular endothelial growth factor; NF-KB binding and activation; phosphorylation of ERK1/2, p38, and JNK1/2; and invasion/migration of the MDAMB-231 cells were downregulated. On the other hand, the expression of tissue inhibitors of matrix metalloproteinases (TIMP-1 and TIMP-2) and plasminogen activator inhibitor (PAI)-1 was upregulated. Cell cycle arrest and apoptosis of the cells ensued (Yang et al. 2011).

A submerged fermentation culture of $A$. camphorata displayed toxicity toward HER-2/neuoverexpressing MDA-MB-453 and BT-474 cells mediated by production of reactive oxygen species. The expression of CDK4, cyclin E, cyclin D1, PI3K/Akt, and downstream effectors $\beta$ catenin and GSK-3 $\beta$ was attenuated. Arrest at sub-G1 phase of the cell cycle, mitochondrial dysfunction, cytochrome c release, DNA fragmentation, PARP degradation, Bcl-2/Bax dysregulation, caspase-3/caspase- 9 activation, and apoptosis were observed (Lee et al. 2012).

Reduced mortality rate and slightly prolonged mean 6-month overall survival and considerable amelioration in sleep quality were found in patients with advanced and/or metastatic 
adenocarcinoma who received standard chemotherapy and A. cinnamomea in conjunction, compared with the control group treated with standard chemotherapy alone. However, patients receiving the combined treatment had reduced thrombocyte counts (Tsai et al. 2016).

The steroid antrocin from A. camphorata impeded proliferation of metastatic breast cancer MDA-MB-231 cells but did not adversely affect nontumorigenic HS-68 cells and MCF10A cells. Antrocin brought about caspase-3 and poly (ADP-ribose) polymerase cleavage. Antrocin downregulated expression of $\mathrm{Bcl}-2, \mathrm{Bcl}-\mathrm{xL}$, and survivin which inhibited apoptosis and their mRNA, but upregulated expression of cytosolic cytochrome $c$ and Bax which promote apoptosis. Antrocin prevented Akt and its downstream effectors NF-kB, mTOR, and GSK-3 $\beta$ from undergoing phosphorylation. Akt downregulation by small interfering RNA before exposure to antrocin promoted apoptosis (Rao et al. 2011). Under the influence of antrocin, breast cancer cell viability was diminished, formation of mammospheres and migration colonies was inhibited, and expression of stemness and oncogenic markers such as $\beta$-catenin, Notch1, and Akt in breast cancer cells was downregulated. Antrocin and paclitaxel administered sequentially demonstrated a synergistic anti-breast action in vitro and in vivo (Chen et al. 2019a).

The ethanolic extract of A. cinnamomea exhibited antiproliferative activity toward MCF-7 cells and tamoxifen-resistant MCF-7 cells. A. cinnamomea extract, together with tamoxifen, displayed higher antiproliferative activity toward tamoxifen-resistant MCF-7 cells than A. cinnamomea extract alone. The mRNA expression of skp2 (S-phase kinase-associated protein 2) was downregulated by enhancing the expression of miR-30-5p, miR-26-5p, and miR-21-5p in MCF-7 as well as tamoxifen-resistant MCF-7 cells (Lin et al. 2018). The ethanolic extract of A. cinnamomea exhibited antiproliferative activity toward T47D breast cancer cells in vitro as well as in vivo by arresting the cancer cells at G1 phase of the cell cycle and also elicited autophagy. The expression of cell cycle-related proteins and activity of histone deacetylases were downregulated. The expression of autophagic marker LC3 II, transcription factor FOXO1 and p62 was enhanced. Involvement of endoplasmic reticulum stress was indicated by upregulated expression of CHOP (C/EBP homologous protein, GRP78/Bip (glucose regulating protein 78), and IRE1 (inositol-requiring enzyme 1a). Tumor growth was suppressed (Chen et al. 2019b).

Antcin-A with potent anticancer and anti-inflammatory activities inhibited, in MCF-7 and MDAMB-231 cells, epithelial-to-mesenchymal transition by enhancing the epithelial markers occludin and $\mathrm{E}$-cadherin and suppressing the mesenchymal markers vimentin and $\mathrm{N}$-cadherin via downregulation of ZEB1 which suppresses their transcription. Antcin-A induced the ZEB1 repressor miR-200 and activates p53 transcription. The tendency of breast cancer cells to migrate and invade was reduced by antcin-A (Kumar et al. 2019). A. cinnamomea at concentrations $(20-60 \mu \mathrm{g} / \mathrm{ml})$ which lacked cytotoxicity prevented the transformation from the fibroblastic to the epithelial phenotype as well as epithelial-to-mesenchymal transition by enhancing expression of E-cadherin. The expression of Twist in human triple-negative breast cancer MDA-MB-231 cells and in Twist-transfected cells was downregulated after exposure to A. cinnamomea. A. camphorata suppressed $W n t / \beta$-catenin nuclear translocation via a pathway involving GSK3 $\beta$. A. camphorata undermined EMT by attenuating expression of mesenchymal marker proteins like fibronectin, N-cadherin, Snail, vimentin, ZEB-1, and augmenting expression of epithelial marker proteins like ZO-1 and occludin. The mushroom thwarted metastasis of breast cancer to the lungs by enhancing pulmonary expression of E-cadherin (Hseu et al. 2019a).

Antrodia salmonea 
A. salmonea arrested MDA-MB-231 cancer cells at G2 phase of the cell cycle by downregulating the levels of cyclin A, B1, E, and CDC2 proteins. Pretreatment with the antioxidant $\mathrm{N}$-acetylcysteine inhibited cell cycle arrest and reversed downregulated $\mathrm{COX}-2$ expression and PARP cleavage. Tumor incidence and growth in athymic nude mice bearing MDA-MB-231-xenografts were suppressed (Chang et al. 2017b).

A. salmonea inhibited, in MDA-MB-231 cells, the PI3K/AKT/NF-KB pathways. The expression of MMP-9, UPA, UPAR, and VEGF and invasion and migration were suppressed. A. salmonea prevented morphological alterations and epithelial-to-mesenchymal transition by suppressing $\mathrm{N}$-cadherin, Snail, vimentin, Twist, and Slug and enhancing E-cadherin. The $\beta$-catenin pathway and Smad3 signaling pathway were downregulated, whereas GSK3 $\beta$ expression was enhanced. Tumor metastasis was suppressed while E-cadherin expression in lung biopsy was enhanced (Hseu et al. 2019b).

\section{Auricularia auricula-judae}

Wild A. auricula-judae displayed antiproliferative activity on MCF-7 human breast cancer cells with IC50 values of $333.3 \mu \mathrm{g} / \mathrm{ml}$ and $285.7 \mu \mathrm{g} / \mathrm{ml}$ for its water extract and ethanol extract, respectively (Novaković et al. 2019).

A tumor-targeted, folic acid (FA)conjugated-Auricularia auricular polysaccharide (AAP)-cisdiaminedichloroplatinum (CDDP) complex (FA-AAP-CDDP complex) demonstrated a more potent antitumor action and elevated uptake compared with the AAP-CDDP complex. The complex was as potent as free cisplatin in anticancer activity in tumor xenograft-bearing nude mice and suppressing the circulating levels of tumor markers. The complex elicited apoptosis by enhancing caspase-3, cytochrome $\mathrm{c}$, and Bax and suppressing Bcl-2, indicating that the complex may trigger the mitochondrial signaling and intrinsic apoptotic pathways. Mice treated with the complex had larger organs and higher activities of the antioxidative enzymes catalase, glutathione peroxidase, and superoxide dismutase and lower serum levels of malondialdehyde than their counterparts treated with cisplatin (Qin et al., 2018a). The complex employed for treatment of cervical carcinoma could heighten the anticancer activity and minimize the untoward toxicity of CDDP. The treated mice had higher renal activities of the antioxidative enzymes, glutathione peroxidase, superoxide dismutase, and catalase; higher levels of interferon- $y$, interleukin-2, and interleukin-4; and reduced levels of malondialdehyde. The expression of caspase-3 and Bax was upregulated, but Bcl-2 expression was downregulated, ensuing in apoptotic death of the cancer cells (Qin et al., 2018b).

\section{Clitocybe alexandri}

Extracts of the Portuguese wild mushroom C. alexandri containing polysaccharides (obtained by boiling water extraction) and phenolic extracts (obtained by methanolic and ethanolic extraction) demonstrated suppressive activity on breast, colon, gastric, and lung cancer cells as well as antioxidant activity (Vaz et al. 2010).

\section{Coprinellus sp., Coprinus comatus, and Flammulina velutipes}

Aqueous extracts of three mushroom species, F. velutipes, C. comatus, and Coprinellus sp., suppressed cell growth as well as tumor colony formation and triggered apoptosis in both estrogen receptor+ and estrogen receptor- MCF-7, MDA-MB-231, and BT-20 breast cancer cells. The IC50 of F. velutipes extract toward BT-20 cells and C. comatus extract toward MDAMB-231 cells were $30 \mu \mathrm{g} / \mathrm{ml}$ and $40 \mu \mathrm{g} / \mathrm{ml}$, respectively. Apoptosis of breast cancer cells was observable using annexin V-FITC within $2 \mathrm{~h}$ of treatment of cells with the extracts and detectable using DNA fragment end-labeling assay (TUNEL) within $5 \mathrm{~h}$ of treatment (Gu and Leonard 2006). 


\section{Coprinus comatus}

Ethanolic and ethyl acetate extracts of $\mathrm{C}$. comatus downregulated the levels of transcripts of androgen and glucocorticoid receptors and androgen receptor protein in MDA-kb2 breast cancer cells (Zaidman et al. 2008).

Both culture liquid crude extract and ethyl acetate extract of $C$. comatus significantly prevented hydrogen peroxide-elicited IkappaBalpha phosphorylation. The ethyl acetate extract suppressed NF-kappaB function. These actions of $\mathrm{C}$. comatus were probably related to its antitumor activity (Asatiani et al. 2011). A 14.4-kDa alkaline protein Y3 from C. comatus fruiting bodies, with the unique $\mathrm{N}$-terminal sequence NRDVAACARFIDDFCDTLTP, inhibited tobacco mosaic virus by $83 \%$ at the concentration of $12.5 \mu \mathrm{g} / \mathrm{ml}$, and inhibited MGC-803 human gastric cancer cells with an IC50 of $12 \mu \mathrm{g} / \mathrm{ml}$ (Wu et al. 2003). Y3 is a glycan-binding protein with GalNAcß1-4 (Fuca1-3) GlcNAc (LDNF) as its specific binding ligand. Y3 is characterized by a single-domain $\alpha \beta \alpha$-sandwich motif, with dimerization of two monomers to produce a tenstranded, antiparallel $\beta$-sheet accompanied by an $\alpha$-helix on both the left and right sides. There is a sizable glycan-binding pocket protruding into the dimeric interface. $Y 3$ triggered apoptosis specifically in human T cell leukemia Jurkat cells. Perturbation of amino acids implicated in interactions between $Y 3$ and LDNF led to a decline of binding to Jurkat $T$ cells and fall in the activity of Y3 (Zhang et al. 2017a).

\section{Cordyceps militaris}

A 12-kDa antifungal protease from $\mathrm{C}$. militaris with a pl of 5.1 displayed a cytotoxic action on human breast cancer cells (Park et al. 2004). Another 10.9-kDa antifungal peptide cordymin exerted an antiproliferative action toward breast cancer MCF-7cells but it was devoid of an effect on colon cancer HT-29 cells, murine splenocytes, and murine macrophages (Wong et al. 2011). C. militaris immunoregulatory protein corresponding to a protein (CCM_01955) in the transcriptional database of $\mathrm{C}$. militaris possessed $18.5 \%$-helix, $35.5 \% \beta$-sheet, $17.0 \%$ turn, and $29.0 \%$ random coil. The protein upregulated mRNA levels of interleukin- 8 and tumor necrosis factor- $\alpha$ in peritoneal macrophages prohibited metastasis and extended survival in mice bearing 4T1 breast cancer xenografts (Yang et al. 2015).

An aqueous extract of $\mathrm{C}$. militaris triggered apoptosis by upsetting mitochondrial function, activating caspase-3 and inactivating Akt (Jin et al. 2008). The aqueous extract lowered cell viability; exerted antiproliferative activity; prevented cell migration; released lactate dehydrogenase; upregulated expression of caspase-3, cleaved caspase-8, cleaved poly (ADPribose) polymerase, and B cell-associated X protein; and enhanced apoptotic rates in MCF-7 cells. The extract manifested anticancer action in nude mice bearing MCF-7 xenografts (Song et al. 2016). The aqueous extract diminished the viability of cultured $4 \mathrm{~T} 1$ breast cancer cells. It depressed serum levels of matrix metalloproteinase-9; inhibited pulmonary metastasis; downregulated pulmonary expression of chemokine ( $\mathrm{C}-\mathrm{C}$ motif) ligand 17, interleukin-33, matrix metalloproteinase-9, and osteopontin; and extended the lifespan of tumor-bearing animals (Cai et al. 2018).

Dietary treatment with C. militaris, especially administration of cordycepin-enriched C. militaris JLM 0636 with 7-fold higher cordycepin concentration, led to suppression of tumor growth and prolongation of survival in $\mathrm{C} 3 \mathrm{H} / \mathrm{He}$ mice bearing $\mathrm{FM} 3 \mathrm{~A}$ breast cancer xenografts. The fall in transforming growth factor- $\beta$ and interleukin-2 secretion and a rise in interleukin- 4 secretion, which took place in the absence of an altered proliferation of concanavalin A-stimulated lymphocytes, indicated changes in the subpopulations of tumor-derived $T$ lymphocytes. CD4+CD25+ cell population and FoxP3+-expressing Treg cells among the CD4+CD25+ population fell in the total splenocytes from mice exposed to JLM 0636 but there were no 
changes in the CD4+ T cell population. However, the populations of CD8+ $T$ cells and interferon-y expressing CD8+ T cells from tumor-bearing mice escalated following JLM 0636 treatment (Jeong et al. 2013).

Cordycepin and C. militaris concentrate exerted antiproliferative activity toward MCF-7 cells with an IC50 value of $9.58 \mu \mathrm{M}$ and $73.48 \mu \mathrm{g} / \mathrm{ml}$, respectively. The targets of cordycepin deduced by employing network pharmacological analysis are largely connected with the hedgehog signaling, apoptosis, p53 signaling, and estrogen signaling pathways. Cordycepin and $\mathrm{C}$. militaris concentrate triggered apoptosis by promoting the of caspase-7, caspase-8, and caspase- 9 cleavage, heightening the ratio of $\mathrm{Bcl}-2$-associated $\mathrm{X}$ protein/B cell lymphoma 2 (Bax/Bcl-2) protein expression, and decreasing the protein expression of $\mathrm{X}$-linked inhibitor of apoptosis protein (XIAP) in breast cancer MCF-7 cells (Lee et al. 2019c).

\section{Cordyceps sinensis}

C. sinensis is a traditional Chinese medicine which has been employed as an anticancer adjuvant. Jinshuibao capsules (JSBC) composed of C. sinensis reinstated the cellular immunological function and brought about amelioration in the quality of life in 36 patients diagnosed with advanced cancer (Zhou and Lin 1995). There are products such as Vita Yin Yang capsules composed of $\mathrm{C}$. sinensis mycelia.

The dietary supplement, MycoPhyto ${ }^{\circledR}$ Complex, represents a mixture of yeast (Saccharomyces cerevisiae) $\beta-1$, 3-glucan, and mycelial extracts from several mushrooms comprising C. sinensis, Coriolus versicolor, Ganoderma lucidum, Grifola frondosa, A. blazei, and Polyporus umbellatus. It exhibited an antiproliferative action on highly invasive MDA-MB231 human breast cancer cells and arrested the cells at the G2/M phase of the cell cycle. The expression of genes regulating the cell cycle (ANAPC2, ANAPC2, BIRC5, cyclin B1, cyclin $\mathrm{H}$, CDC20, CDK2, CKS1B, Cullin 1, E2F1, KPNA2, PKMYT1, and TFDP1) was downregulated. The metastatic behavior of the cancer cells, cell adhesion, cell migration, and cell invasion associated with downregulation of secretion of the urokinase plasminogen activator, were all inhibited (Jiang and Sliva 2010).

Orally administered C. sinensis did not curtail pulmonary metastasis in a surgical excision model of metastatic mammary carcinoma but was devoid of a suppressive effect on primary tumor growth in vivo, signifying an association of its antimetastatic action with the action of macrophage-derived factors on the tumor cell cycle (Jordan et al. 2010).

Cordycepin (3-deoxyadenosine) from C. sinensis expressed cytotoxicity on cultured MDA-MB231 and MCF-7 human breast cancer cells (Choi et al. 2011; Wang et al. 2016). Under the influence of cordycepin, the cell viability plummeted, cellular proliferation declined, cellular liberation of lactate dehydrogenase increased and reactive oxygen species generation rose, mitochondrial function was disrupted, and nuclear apoptosis took place in human breast cancer cells. Expression of the antiapoptotic protein B cell lymphoma $2(\mathrm{Bcl}-2)$ was downregulated whereas that of pro-apoptotic proteins such as Bax, caspase-3, caspase-8, and caspase-9 was upregulated. Growth of MCF-7-xenograft in nude mice was impeded (Wang et al. 2016).

Cordycepin suppresses tumor growth via upregulating tumor apoptosis and autophagy, eliciting cell cycle arrest, producing DNA damage, and targeting cancer stem cells in cancer cells. Cordycepin exerts its antimetastatic action by suppressing cancer metastasis-associated pathways through impeding cancer cell-induced platelet aggregation and attenuating cancer cell invasiveness by inactivating matrix metalloproteinase- 2 and metalloproteinase- 9 and upregulating cancer cell secretion of tissue inhibitor of metalloproteinase-1 and metalloproteinase-2. Cordycepin produces its anticancer action through inhibition of cyclin D1 
and activation of adenosine A3 receptor as well as glycogen synthase kinase. The associated molecular pathways entail the enzymes caspases, glycogen synthase kinase 3 beta and mitogen-activated protein kinases, and receptors comprising death receptors, adenosine receptors, and epidermal growth factor receptors (Nakamura et al. 2015; Jin et al. 2018; Khan and Tania 2018; Qin et al. 2019).

Coriolus versicolor (also known as Yunzhi and green Lingzhi, a member of five-color Lingzhi)

Yunzhi has been used as a traditional mushroom in China for over two millennia. Yunzhi has been in routine clinical practice in Japan since 1977 and in China since 1987. Coriolus versicolor PSK (polysaccharide-K from the CM-101 strain) and PSP (polysaccharide from the COV-1 strain) possess a high molecular weight close to $100 \mathrm{kDa}$ and are chemically similar except for the presence of fucose in PSK and rhamnose and arabinose in PSP ( $\mathrm{Ng}$ and Chan, 1997). PSP contributes to prolonging survival and bettering the quality of life, not only in cancer patients but also in patients afflicted with hepatitis, hyperlipidemia, and other chronic diseases. The results of an analysis of over 40 independent PSP-related preclinical and clinical studies conducted in China during the last four decades based on searches of the Chinese VIP, CNKI, and Wanfang databases lend credence to the utilization of Yunzhi as an immunotherapeutic adjuvant (Chang et al. 2017a).

Coriolus versicolor PSK

C. versicolor extract antiproliferative activity toward MCF-7, MDA-MB-231, and T-47D cells and stimulated nucleosome formation in the apoptotic breast cancer cells (Ho et al. 2005). An aqueous extract of $C$. versicolor prohibited migration and invasion of $4 \mathrm{~T} 1$ breast cancer cells. It also downregulated the activities and tumor necrosis factor- $\alpha$, interferon- $\gamma$, interleukin-2, interleukin-6, and interleukin-12) inducing roles in xenograft-bearing mice (Luo et al. 2014).

Dietary PSK reduced cancer incidence and increased survival rates in $\mathrm{C} 3 \mathrm{H} / \mathrm{OuJ}$ mice developing spontaneous tumors (Fujii et al. 1988). PSK improved the survival of operable breast cancer patients demonstrating vascular invasion who received oral adjuvant combination chemotherapy of 5-fluorouracil, cyclophosphamide, mitomycin $\mathrm{C}$, and prednisolone following surgery (lino et al. 1995).

PSK (5\%solution) when administered by local injection was useful for managing nodular or scattered-type locally recurrent breast cancers with the exception of cancers of the infiltrating type (Asaishi et al. 1988). PSK at a high dose but not at a low-dose downregulated estrogen receptors and progesterone receptors in MCF-7 cells (Aoyagi et al. 1997). PSK downregulated HSP47 and HSP60 but not HSP72/73 expression in human tumor cell lines (Morino et al. 1997). PSK exhibited an antiproliferative effect on breast cancer cells, arrested cells in G0/G1 phase of the cell cycle, upregulated caspase-3 expression, and triggered apoptosis. PSK potentiated the proliferative activity of interleukin-2 toward peripheral blood lymphocytes (Jiménez-Medina et al. 2008). PSK is a potent Toll-like receptor 2 (TLR2) agonist. Under the influence of PSK, interferon- $\gamma$ is produced by human NK cells through direct and indirect interleukin-12-dependent actions. PSK augmented antibody-dependent cell-mediated cytotoxicity of the monoclonal antibody trastuzumab against MDA-MB-231 and SKBR3 breast cancer cells. PSK potentiated the antitumor effect of anti-HER2/monoclonal antibody therapy in neu transgenic mice (Lu et al. 2011). PSK inhibited tumor growth in mice implanted with cells devoid of Rae-1 and H60 expression but not in animals with Rae-1 and H60 expression. The expression of natural killer group 2, member D ligands (NKG2DLs) correlated with the anticancer activity of PSK (Konagai et al. 2017). PSK prolonged 5-year survival in patients with colorectal, esophageal, gastric, nasopharyngeal, and non-small cell lung cancers.

Coriolus versicolor PSP 
Upregulated formation of tumor necrosis factor, reactive oxygen intermediates (superoxide anions), and reactive nitrogen intermediates by peritoneal macrophages was observed in inbred C57 mice in response to PSP (Liu et al. 1993). Extramycelial and intramycelial materials obtained from mycelial culture of $\mathrm{C}$. versicolor displayed stimulatory effects on macrophages as well as splenocytes (Wang et al. 1996). PSP had analgesic activity but was without deleterious effects on ovarian steroidogenesis, ovulation, midterm gestation, and embryo development in mice ( $\mathrm{Ng}$ and Chan 1997).

PSP prolonged 5-year survival in esophageal cancer patients and exerted immunostimulatory effects on patients with cervical, esophageal, gastric, lung, and ovarian cancers. PSK and PSP attenuated symptoms caused by cancer chemotherapy (Kidd 2000). Additional treatment in the form of $3 \mathrm{~g}$ of oral PSK daily for 2 years displayed a benefit in patients with node-negative, estrogen receptor-negative, and stage IIA T2N1 cancer receiving mitomycin C and Ftorafur chemotherapy when examined at 5-year follow-up (Toi et al. 1992).

PSP augmented the apoptotic effect of etoposide and doxorubicin by forming an S-phase trap in ZR-75-30 human breast cancer cells (Wan et al. 2008). The stimulatory action of C. versicolor extract, enriched in protein-bound polysaccharides, on blood lymphocyte proliferation as well as interlekin- $1 \beta$ and interlekin- 6 mRNA expression was mitigated in feverrange hyperthermia (Pawlikowska et al. 2016). A combination of $C$. versicolor in conjunction with metronomic zoledronate exerted an antitumor action in an intratibial breast tumor model and prevented osteoclastic activity. The incidence of hepatic and pulmonary metastasis remained unchanged (Ko et al. 2017). Zoledronate exerted an antitumor action in intratibial breast tumor model and prevented osteoclast activity. The incidence of hepatic and pulmonary metastasis remained unchanged (Ko et al. 2017).

PSP upregulated genes of interleukin-12, interleukin-6, and tumor necrosis factor- $\alpha$ via control of the TLR4-TIRAP/MAL-MyD88 signaling pathway in peripheral blood mononuclear cells collected from breast cancer patients (Wang et al., 2013). C. versicolor protein-bound polysaccharides exhibited tumor necrosis factor-a-dependent antiproliferative activity toward MCF-7 cells and augmented the proliferative response of blood lymphocytes which was associated with interleukin- 6 and interleukin-1 $\beta$ mRNA upregulation (Kowalczewska et al. 2016).

Ergosta-7,22-dien-3 beta-ol is a patented C. versicolor ingredient with anticancer and antiherpes simplex virus activities (Chan 2009). The C. versicolor product GE Yunzhi Essence (Vita Green) is composed of an array of anticancer and immunostimulatory ingredients comprising PSP, polysaccharides, beta-glucans, lignins, and ergosta-7, 22-dien-3 beta-ol. MycoPhyto® Complex, a mixture of C. versicolor, Cordyceps sinensis, Grifola frondosa, G. lucidum, Polyporus umbellatus, and A. blazei mushrooms and Saccharomyces cerevisiae $\beta$ 1,3-glucan displayed antiproliferative activity and arrested MDA-MB-231 cells at the G2/M phase of the cell cycle. Expression of genes regulating the cell cycle (ANAPC2, BIRC5, CDC20, CDK2, CKS1B, cyclin B1, cyclin H, Cullin 1, E2F1, PKMYT1, KPNA2, and TFDP1 was downregulated. Cell adhesion, cell migration, cell invasion, and urokinase plasminogen activator secretion of the cells were suppressed (Jiang and Sliva 2010). Another dietary supplement BreastDefend, composed of mushroom (C. versicolor, Phellinus linteus, and G. lucidum) extracts, medicinal herbs (Curcuma longa, Astragalus membranaceus, and Scutellaria barbata), and quercetin and diindolylmethane, manifested antiproliferative and antimetastatic activity toward MDA-MB-231 cells in vitro. Oral administration of BreastDefend (100 mg/kg for 4 weeks) did not produce organ damage in tumor-bearing mice. BreastDefend exhibited antitumor and antimetastatic actions in tumor-bearing mice. This was associated with attenuated expression of $\mathrm{C}-\mathrm{X}-\mathrm{C}$ chemokine receptor-4 and urokinase and plasminogen activator gene expression in breast tumors (Jiang et al. 2012). 
Systematic review and meta-analysis of the effect of $\mathrm{C}$. versicolor on survival in cancer patients from 13 clinical trials disclosed a $9 \%$ reduction in 5-year mortality of cancer patients caused by treatment with $\mathrm{C}$. versicolor, resulting in one additional patient alive for every 11 patients treated. The action was more pronounced in breast cancer, colorectal cancer, and gastric cancer patients undergoing chemotherapy (Eliza et al. 2012).

Yunzhi (PSP) greatly uplifts the quality of life of cancer patients undergoing chemotherapy or radiotherapy (Eng 2010). It alleviates chemotherapy-induced side effects including weakness, inappetence, vomiting, dryness of throat, spontaneous sweating, and pain symptoms $(\mathrm{Ng}$ 1998).

Flammulina velutipes

Aqueous extract of the golden needle mushroom F. velutipes virtually eliminated MCF-7 tumor colony formation rate, whereas its counterparts from Coprinus comatus and Coprinellus sp. decreased colony formation by $60 \%$ (Gu and Leonard 2006). Lower cancer death rates were found in Japanese farmers engaged in F. velutipes farming than people not involved in the same activity (Monro 2003).

There are other constituents that have been shown to inhibit other cancer cells. F. velutipes polysaccharides inhibited murine melanoma B16F10 cells (Chen et al. 2018) and myelogenous leukemia K562 cells (Jia et al. 2017) in vitro and murine lymphocytic leukemia P 388 in vivo (Krasnopolskaya et al. 2016). Fungal immunomodulatory protein inhibited A549 lung cancer cells (Chang et al. 2013). F. velutipes sterol liposomes inhibited HepG2 hepatoma cells (Yi et al. 2013a) F. velutipes sterol nanomicelles inhibited neuroblastoma U251 cells and HeLa cells (Yi et al. 2013b).

\section{Fomes fomentarius}

The ethanolic extract of F. fomentarius arrested MDA-MB-231 cells in the sub-G1 phase in the cell cycle; upregulated expression of E-cadherin, cleaved poly diphosphate (ADP-ribose) polymerase, and cleaved caspase- 9 and caspase-3; and triggered apoptosis in MDA-MB-231 cells. The extract reduced viability and migration of MDA-MB-231 breast cancer cells. It downregulated Akt phosphorylation and expression of cyclin $A / E$, cyclin-dependent kinase 2, and S-phase kinase-associated protein, B cell lymphoma 2, and matrix metalloproteinase-9. Betulin in the extract inhibited p-AKT in MDA-MB-231 cells. Thus, the phosphoinositide 3kinase/AKT pathway was suppressed (Lee et al., 2019b).

Fomitopsis officinalis (also known as white Lingzhi, a member of five-color Lingzhi)

Water and ethanolic extracts of white Lingzhi exhibited antiproliferative activity against breast cancer cells (Zhang et al. 2017a). F. officinalis has been used for the treatment of gastric cancer (Feng et al. 2010).

\section{Fuscoporia torulosa}

Fractionation of the methanolic extract of $F$. torulosa revealed the presence of $5 \alpha, 8 \alpha-$ epidioxyergosta-6,22-dien-3ß-il-palmitate and ten compounds (compounds 2 to 11). The methanolic extract and one of the compounds, compound 8, exhibited indicated high inhibitory potency against MCF-7 cells and butyrylcholinesterase (Deveci et al. 2019).

\section{Ganoderma atrum}

rFIP-gat, the recombinant form of the fungal immunomodulatory protein FIP-gat from Ganoderma atrum, brought about agglutination and decreased viability of MDA-MB-231 breast cancer cells with an IC50 of $5 \mu \mathrm{g} / \mathrm{ml}$ and $9.96 \mu \mathrm{g} / \mathrm{ml}$, respectively. At $10 \mu \mathrm{g} / \mathrm{ml}$, rFIP-gat arrested 
the cancer cells in the G1/S phase of the cell cycle, inhibited cell proliferation, and elicited apoptosis (Xu et al. 2016a).

\section{Ganoderma lipsiense}

G. lipsiense extract administered to BALB/c nude mice reduced the microvessel density and cyclin D1-positive cell count but raised the thrombospondin 1-positive cell count and thereby inhibited growth of MDA-MB-231-HM in mice (Qi et al. 2016).

Ganoderma lucidum (also known as red Lingzhi, a member of five-color Lingzhi)

Ethanolic and ethyl acetate extracts of $G$. lucidum downregulated levels of transcripts of androgen and glucocorticoid receptors and androgen receptor protein in breast cancer MDAkb2 cells (Zaidman et al. 2008).

G. lucidum is a highly popular nutraceutical worldwide and has been used to clinical trials for breast cancer and non-small cell lung cancer (Hsu and Cheng 2018). G. lucidum may reduce cancer-related fatigue and improve quality of life in breast cancer patients receiving hormonal therapy (Zhao et al., 2012). Following oral administration of G. lucidum extract for 1 month, the growth of large mammary tumors from MDA-MB-231 cells was reduced, expression of genes implicated in invasive behavior (FN1, HRAS, MCAM, I2PP2A, S100A4, and VIL2,) was inhibited, and MDA-MB-231 cell migration was prohibited after gene silencing by siRNA (Loganathan et al. 2014). Sixty patients who failed two or more courses of chemotherapy for their gynecologic cancer were randomly assigned to three groups. Twenty daily consumed 6 $\mathrm{g}$ of Ganoderma lucidum in form of water extract for 12 weeks; 20 others $6 \mathrm{~g}$ of Ganoderma lucidum spores and the rest took placebo. Stable disease was observed in $0 \%, 50 \%$, and $38.1 \%$, and 1 -year overall survival was $44 \%, 60 \%$, and $63.6 \%$ in the groups receiving placebo, G. lucidum spore, and G. lucidum water extract, respectively (Suprasert et al. 2015).

An alcohol extract of $\mathrm{G}$. lucidum exhibited antiproliferative and apoptosis-inducing activity toward MCF-7 cells via enhancement of p21/Waf1 and pro-apoptotic Bax and suppression of cyclin D1 (Hu et al. 2002). G. lucidum downregulated urokinase-type plasminogen activator receptor expression and urokinase-type plasminogen activator secretion. This brought about suppression of the migration of MDA-MB-231 cells (Sliva et al. 2002). G. lucidum extracts impeded the production of interleukin-6, interleukin-8, matrix metalloprotease-2, and matrix metalloprotease- 9 in cancer cells exposed to lipopolysaccharide. The viability and cell migration of MDA-MB 231 cells was impaired (Barbieri et al. 2017). G. lucidum extract inhibited the growth of tumors arising from MDA-MB-231 cells implanted into mammary fat pads of nude mice, reduced pulmonary metastases, and attenuated expression of invasiveness-associated genes (FN1, HRAS, I2PP2A, MCAM, S100A4, and VIL2) in MDA-MB-231 cells (Loganathan et al. 2014). G. lucidum reduced estrogen receptor alpha expression in MCF-7 cells but not estrogen receptor beta expression in either MCF-7 or MDA-MB-231 cells. G. lucidum suppressed estrogen-dependent and constitutive transactivation activity of estrogen receptor through estrogen response element (Jiang et al. 2006). G. lucidum reduced the telomerase activity and downregulated hsa-miR-27a and upregulated miR-1207-5p, hsa-miR-1285, and miR-3687 (Gonul et al. 2015). G. lucidum extract suppressed AKT and ERK signaling pathways and rendered SUM-149 cells more sensitive to erlotinib (epidermal growth factor receptor tyrosine kinase inhibitor used in the treatment of non-small cell lung cancer) erlotinib/G. lucidum extract undermined SUM-149 cell viability, exerted antiproliferative activity, and repressed cell migration and invasiveness (Suárez-Arroyo et al. 2016). G. lucidum reduced the phosphorylation of Wnt co-receptor LRP6 and expression of Wnt3a-activated Wnt target gene Axin2. The Wnt/ $\beta$-catenin signaling was suppressed. Wnt-induced hyperproliferation of breast cancer cells was impaired and MDA-MB-231 cell migration was impeded 
(Zhang 2017). G. lucidum extract downregulated the transducer and activator of transcription 3 (STAT3) pathway and NANOG, OCT4, and SOX2 expression in breast cancer stem cells (Rios-Fuller et al. 2018). Exposure of MDA-MB-231 cells to G. lucidum extract brought about diminution of cell viability, cell migration, and invasiveness Rac activity, expression of Cdc42, c-Myc, ENA/VASP, p-FAK (Tyr925), and lamellipodin, and lamellipodia formation (AcevedoDíaz et al. 2019). There was a decline in incidence of mammary cancer in mice caused by administration of dimethylbenz[a]anthracene after treatment with G. lucidum (Smina et al. 2017).

Khz (formed from the fusion of $G$. lucidum and Polyporus umbellatus) elevated intracellular levels of calcium and reactive oxygen species and activities of caspase-7, caspase-8, and caspase- 9 leading to reduced proliferation and apoptosis in MCF-7 cells (Kim et al. 2016). The fungal immunomodulatory protein Ling Zhi-8 (LZ-8) from G. lucidum stimulates dendritic cells and can serve as the adjuvant of a cancer DNA vaccine (Chu et al. 2011).

A fucose-containing fraction of G. lucidum (FFLZ) worked via the caveolin-1/Smad7/Smurf2dependent ubiquitin-mediated degradation of transforming growth factor- $\beta$ receptor to prevent breast cancer cell migration and the epithelial-to-mesenchymal transition phenotype, decreased tumor growth, and prohibited metastatic spread. FFLZ synergized with trastuzumab to lower the viability of human breast cancer cells resistant to trastuzumab (Tsao and Hsu 2016).

G. lucidum polysaccharide has been used for treating atrophic myotonia, dermatomyositis, muscular dystrophy, neurosis, and polymyositis in China in the last four decades (Zhang et al. 2019a). SeGLP-2B-1, a selenium-containing polysaccharide from selenium-enriched G. lucidum mycelia possessed a 150-fold higher level of selenium compared with regular polysaccharide GLP-2B-1 exhibited and a 10-fold higher potency in suppressing proliferation of six types of human tumor cells indicating the pivotal part played by selenium in the antiproliferative activity of SeGLP-2B-1 (Shang et al. 2009). SeGLP-2B-1 inhibited the growth of MCF-7 cells; disrupted the mitochondrial membrane potential; triggered cytochrome $\mathrm{C}$ release into the cytoplasm; increased the activities of enhanced activities of caspase-3, caspase-9, and poly (ADP-ribose) polymerase; elicited DNA ladder formation; arrested the cells in sub-G1 phase of the cell cycle; and triggered apoptosis (Shang et al. 2011).

Oil prepared from $\mathrm{G}$. lucidum spores with broken sporoderm upregulated caspase-3 and Bax and the mitochondrial apoptotic pathway but not caspase-8 expression in MDA-MB-231 cells. The spore oil inhibited proliferation of the breast cancer cells in vitro and tumor growth in tumorbearing animals (Jiao et al. 2020). There are products such as Vita Green cracked Lingzhi spores.Spoderm-broken spores have higher activity than uncracked spores.

G. lucidum spore polysaccharide in conjunction with paclitaxel rectified paclitaxel-induced abnormalities in microbiota in such a way that Ruminococcus, Bacteroides, and five other genera were increased, whereas Odoribacter and Desulfovibrio carrying cancer risk were reduced (Su et al. 2018). In response to administration of an extract of sporoderm-broken G. lucidum spores, 4T1-breast cancer xenograft growth in mice was retarded, cytotoxic $T$ cell population and the ratio of cytotoxic $\mathrm{T}$ cell to helper $\mathrm{T}$ cell in peripheral blood were elevated, and splenic programmed cell death protein-1 and cytotoxic $T$ lymphocyte antigen-4 in the xenograft underwent a decline (Su et al. 2018).

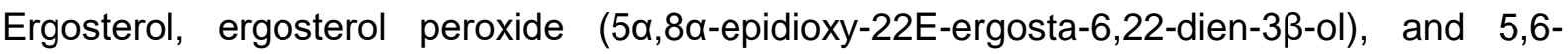
dehydroergosterol (ergosta-7,22-dien-3beta-ol) from $\mathrm{G}$. lucidum demonstrated antiproliferative activities in vitro. In triple-negative/inflammatory breast cancer cells, ergosterol peroxide arrested cells in G1 phase of the cell cycle, exhibited antiproliferative activity, activated 
caspase-3/7 and PARP cleavage, and diminished migration and invasiveness of cancer cells. Ergosterol peroxide attenuated the expression of total AKT1, AKT2, BCL-XL, cyclin D1, and cMyc in inflammatory breast cancer cells. Its derivative ergosterol peroxide sulfonamide displayed high potency in inflammatory breast cancer cells and therapeutic index in comparison with normal cells (Martínez-Montemayor et al. 2019).

Ganodermanontriol [24S, 25R)-24,25,26-trihydroxylanosta-7,9(11)-dien-3-one] inhibited colony formation (anchorage-independent growth) and proliferation (anchorage-dependent growth) of MDA-MB-231 human breast cancer cells. Expression of the cell cycle regulatory protein CDC20 overexpressed in precancerous and breast tissues was attenuated. Urokinase plasminogen activator secretion, urokinase plasminogen activator receptor MDA-MB-231 expression, and invasive behavior (cell adhesion, cell migration, and cell invasion) were inhibited (Jiang et al. 2011).

Ganoderic acid DM [(Z,6R)-2-methyl-6-[(5R,10S,13R,14R,17R)-4,4,10,13,14-pentamethyl3,7-dioxo-2,5,6,11,12,15,16,17-octahydro-1H-cyclopenta[a]phenanthren-17-yl]hept-2-enoic acid] arrested MCF-7 cells in G1 phase of the cell cycle; decreased c-Myc, cyclin D1, CDK2, CDK6, and $\mathrm{p}-\mathrm{Rb}$; disrupted mitochondrial membrane potential; and elicited DNA fragmentation and PARP cleavage in MCF-7 cells (Wu et al. 2012b).

Ganoderic acid Me [(E)-6-(3,15-diacetyloxy-4,4,10,13,14-pentamethyl-2,3,5,6,12,15,16,17octahydro-1H-cyclopenta[a]phenanthren-17-yl)-2-methylhept-2-enoic acid] downregulated expression of NF-kB-regulated genes including cell proliferation genes (cyclin D1 and c-Myc), genes inhibiting apoptosis (Bcl-2), angiogenesis (interleukin-6, interleukin-8, and vascular endothelial growth factor) and invasiveness gene (matrix metalloproteinase-9) in MDA-MB231 cells. Tumor growth of MDA-MB-231 cells in xenograft-bearing mice was inhibited ( $\mathrm{Li}$ et al. 2012). Ganoderic acid A [(2R,6R)-6-[(5R,7S,10S,13R,14R,15S,17R)-7,15-dihydroxy4,4,10,13,14-pentamethyl-3,11-dioxo-2,5,6,7,12,15,16,17-octahydro-1H-

cyclopenta[a]phenanthren-17-yl]-2-methyl-4-oxoheptanoic acid] increased generation of reactive oxygen species, downregulated phosphorylation of JAK2 and impeded STAT3 downstream activation, and inhibited STAT3 target gene expression, such as B cell lymphomaextra-large and myeloid cell leukemia 1, leading to high concentrations of proteins implicated in mitochondrial apoptosis and cyclin-dependent kinase inhibitors in MDA-MB-231 cells (Yang et al. 2018).

Ganoderiol A-enriched extract acted on MDA-MB-231 cells by downregulating active forms of focal adhesion kinase (FAK) and impairing FAK-SRC interaction; inactivating paxillin; attenuating expression of $\mathrm{Cdc} 42$, Rac1, and RhoA; and interrupting interaction between neural Wiskott-Aldrich syndrome protein (N-WASP) and Cdc42. The FAK-SRC-paxillin signaling pathway was repressed followed by suppressive effects on cell migration and adhesion (Wu et al. 2013).

\section{Ganoderma resinaceum}

The phytosterol $\alpha$-spinasterol from $\mathrm{G}$. resinaceum mycelial extract inhibited MDA-MB-231 and MCF-7 breast cancer cells. It downregulated cyclin-dependent kinases cdk4/6 and produced cell cycle arrest in G0-G1 phase. In contrast, it upregulated expression of apoptotic marker Bax and tumor suppressor p53 (Sedky et al. 2018).

Ganoderma sinense (also known as purple Lingzhi, a member of five-color Lingzhi)

Ethanolic extracts from both $\mathrm{G}$. lucidum and $\mathrm{G}$. sinense disrupted mitochondrial membrane potential and brought about cell cycle arrest in breast cancer cells (Liu et al. 2009). Water and 
ethanolic extracts exhibited antiproliferative activity against breast cancer cells (Zhang et al. 2017a).

Ganoderma sinense, also known as purple "Lingzhi," has been employed for twenty century years in China. Tablets composed of $G$. sinense polysaccharide were approved by Chinese State Food and Drug Administration in 2010 as an adjunct therapeutic in China for hematopoietic damage and leukopenia brought about by radiotherapy or chemotherapy of cancer. G. sinense polysaccharide has anticytopenia, antioxidant, antitumor, and detoxifying activities distinct from those of its G. lucidum counterpart (Zhang et al. 2019b).

Five-color Lingzhi is a mixture of the medicinal mushrooms green Lingzhi Coriolus versicolor, red Lingzhi G. lucidum, purple Lingzhi G. sinense, black Lingzhi A. rugosa, yellow Lingzhi L. sulphureus, and white Lingzhi F. officinalis. It is well-known and available in the Orient.

Ganoderma tsugae var. jannieae

The ethyl acetate extract of G. tsugae mycelia downregulated more than $70 \%$ of the reporter activity in MCF7 cells and suppressed IKBa phosphorylation (Chan et al. 2015).

Grifola frondosa (maitake mushroom)

The Clinical Practice Committee of The Society of Integrative Oncology has listed dietary supplements including maitake mushrooms which cancer patients may consume without informing their physicians. The purpose of the information was to alert physicians of the possible use of these dietary supplements by their cancer patients and allow them to discuss the advantages and disadvantages of taking these dietary supplements with cancer patients (Frenkel et al. 2013).

Thirty-four postmenopausal breast cancer patients, free of disease after initial treatment, were recruited for a phase I/II trial. The most prominent functional alterations in response to oral $\mathrm{G}$. frondosa polysaccharide extract $(5-7 \mathrm{mg} / \mathrm{kg}$ daily) with elevations exceeding $50 \%$ were observed in response of granulocytes to phorbol myristate acetate stimulation, including TNFa production from lipopolysaccharide-stimulated CD3+ cells, IL-2 production from unstimulated CD56+ CD3+ cells, and IL-10 production from phorbol myristate acetate stimulated CD3+ cells and CD14+ cells. The most pronounced phenotypic modifications were noted in CD3+ CD56+ NK T cells and CD4+ CD25+ T cells (50\% rise above baseline values) in response to $G$. frondosa extract (10 mg/kg daily). In contrast, IFN-y production by phorbol myristate acetatestimulated CD45RA+ CD4+ cells was reduced by approximately one fifth in response to $G$. frondosa extract (10 $\mathrm{mg} / \mathrm{kg}$ daily) (Deng et al. 2009).

Maitake D-Fraction produced its anticancer effects in mice harboring cancer xenografts via immunostimulatory effects on macrophages, natural killer cells, and T cells. D-Fraction reduced the size of mammary, hepatic, and pulmonary cancers in cancer patients receiving chemotherapy and simultaneous immunotherapy with D-Fraction. D-Fraction alone, without concurrent therapy using anticancer drugs, inhibited metastasis, downregulated tumor marker expression, and augmented natural killer cell activity in all cancer patients (Kodama et al. 2003).

Maitake D-Fraction triggered release of cytochrome $\mathrm{c}$ from mitochondria and thus mitochondrial dysfunction and apoptosis in MCF7 cells (Soares et al. 2011). Maitake DFraction activated macrophages, natural killer cells, and T cells. It altered the expression of genes such as BCL2-antagonist/killer 1 (BAK1), CAV-1, Cul-3, cyclin E, ICAM3, IGFBP-7, ITGA2, NRF2, ST7, SOD2, and SPARC implicated in induction of multidrug sensitivity, cell cycle arrest, inhibition of cell growth and proliferation, induction of apoptosis, and suppression of migration and metastasis (Alonso et al. 2013). Maitake D-Fraction Pro4X inhibited 
carcinogenesis, angiogenesis, and cancer invasiveness and prolonged survival in BALB/C mice bearing breast tumor xenograft (Roldan-Deamicis et al. 2016).

Maitake D-Fraction enhanced cell-cell adhesion by upregulating E-cadherin protein levels, $\beta$ catenin membrane localization, and cell-substrate adhesion. It downregulated cell motility by modifying actin cytoskeleton rearrangements, suppressed activities of matrix metalloproteinase-2 and matrix metalloproteinase-9 implicated in metastasis, repressed invasiveness, and diminished viability of MDA-MB-231 cells. D-Fraction impeded tumor growth and curtailed pulmonary metastases in a murine model bearing tumor xenograft (Alonso et al. 2017, 2018).

G. frondosa polysaccharides enhanced lactate dehydrogenase release and reactive oxygen species accumulation; triggered mitochondrial dysfunction; upregulated expression of Bax, cleaved caspase-3, and caspase-8; and downregulated expression of B cell lymphoma 2 (Bcl2) and Bcl-extra large (Bcl-xL) in MCF-7 and MDA-MB-231 breast cancer cells and cancer tissues of mice treated with the polysaccharides. The polysaccharides suppressed phosphorylation of extracellular signal-regulated kinases and AKT/glycogen synthase kinase$3 \beta$ leading to inhibition of tumor xenograft growth (Zhang et al. 2017b).

\section{Hericium erinaceum}

The 51-kDa Hericium erinaceum agglutinin demonstrated antiproliferative activity toward MCF7 cells with an IC50 of $76.5 \mu \mathrm{M}$ (Li et al. 2010a).

\section{Hypsizigus marmoreus}

Marmorin, a $9.5-\mathrm{kDa}$ ribosome inactivating protein from $\mathrm{H}$. marmoreus displayed antiproliferative activity toward breast cancer MCF-7 cells with an IC50 of $5 \mu \mathrm{M}$. Compared to ribosome inactivating proteins from bitter gourd, garden pea, ridge hairy gourd, gourd, and the mushroom F. velutipes, marmorin exhibited higher antiproliferative activity toward MCF-7 cells and lower translation-inhibitory activity (Wong et al. 2008). Estrogen receptor-positive MCF7 cells were more susceptible to the toxicity of marmorin than estrogen receptor-negative MDAMB-231 cells as reflected in arrest in G2/M-phase of the cell cycle, mitochondrial membrane potential depolarization, and caspase- 9 activation. The activity on estrogen receptor-positive MCF7 cells dwindled following receptor knockdown. The endoplasmic reticulum stress pathway (involving IRE1 $\alpha$ and PERK phosphorylation, caspase-12 cleavage, and CHOP expression upregulation) and death receptor apoptotic pathway (involving caspase-8 activation) were upregulated in response to marmorin in both MDA-MB-231 and MCF7 cells (Pan et al. 2013).

\section{Inonotus obliquus}

Lanosterol, 3beta-hydroxy-lanosta-8,24-dien-21-al, and inotodiol [(3ß,22R)-lanosta-8,24diene-3,22-diol] from I. obliquus suppressed growth in MCF-7 cells. Subfraction 1 of the ethyl acetate fraction was more active than subfractions 2 and 3 (Chung et al. 2010). Trametenolic acid and ergosterol peroxide from ethyl acetate and petroleum ether extracts of I. obliquus exhibited pronounced toxicity toward breast carcinoma MDA-MB-231 cells (Ma et al. 2013). Silver nanoparticles produced from silver nitrate solution at room temperature using I. obliquus extract demonstrated antiproliferative activity toward MCF-7 human breast cancer cells and A549 human lung cancer cells besides ABT radical scavenging activity and activity against both gram-positive and gram-negative bacteria (Nagajyothi et al. 2014).

Laetiporus sulphureus (also known as yellow Lingzhi, a member of five-color Lingzhi) 
Both the mycophenolic acid derivative from cultured L. sulphureus, 6-((2E, 6E)-3,7,11trimethyldedoca-2,6,10-trienyl)-5,7-dihydroxy-4-methylphtanlan-1-one and another compound inhibited proliferation of MCF-7 cells with IC50 value of $36 \mu \mathrm{M}$ (Fan et al. 2014; He et al. 2015).

\section{Lentinus crinitus}

Panepoxydone [(1S,5R,6S)-5-hydroxy-3-[(1S)-1-hydroxy-3-methylbut-2-enyl]-7-oxabicyclo [4.1.0]hept-3-en-2-one] from fermentation of $L$. crinitus inhibited I kappa $B$ a 9 (inhibitor of NFKB) phosphorylation and kept the NF-kappa B complex inactive (Erkel et al. 1996). Panepoxydone exerted antiproliferative activity on MCF-7, MDA-MB-231, MDA-MB-468, and MDA-MB-453 breast cancer cells. Invasion and migration were attenuated and apoptosis was triggered in the cell lines. Expression of cleaved Bax and PARP was augmented, whereas expression of Bcl-2, caspase-3, cyclin D1, and survivin was undermined. FOXM1 was downregulated leading to a reversal of EMT (Arora et al. 2014).

\section{Lentinula edodes/Lentinus edodes}

Ten breast cancer patients treated with cyclophosphamide, epirubicin, and 5-fluorouracil every 21 days for two cycles and then with L. edodes mycelial extract during the second cycle. Lentinus edodes mycelial extract prohibited the reduction in natural killer cell activity and leukocyte count (Nagashima et al. 2005). Three patients undergoing postoperative adjuvant chemotherapy for breast cancer underwent the first course of treatment (chemotherapy only) and the second course of treatment (chemotherapy plus concomitant administration of $L$. edodes mycelial extract). Enhancements in immunosuppressive acidic protein levels, activity of natural killer cells, and quality of life of patients were discernible only after the second course of combined therapy. No undesirable side effects were caused by administration of L. edodes mycelial extract (Yamaguchi et al. 2011). Twenty breast cancer patients received only estrogen-targeted hormone therapy during the first 4 weeks with no detectable alterations in the quality of life or cytokines. However, improvements were produced by combination treatment with hormone therapy and L. edodes mycelial extract in the subsequent 8 weeks (Suzuki et al. 2013). Aqueous extracts of L. edodes mycelial and fruit body extracts exerted antiproliferative and apoptotic actions on MCF-7 cells and proliferative actions on rat thymocytes in vitro and potentiated the proliferative actions of T mitogens on rat thymocytes in vitro (Israilides et al. 2008). The ethyl acetate fraction of L. edodes induced apoptosis in MCF7 and MDA-MB-453cancer cells via upregulating Bax and colk inhibitor p21, downregulating cdk4 and cyclin D1, and bringing about cell cycle arrest (Fang et al. 2006).

L. edodes $\beta$-glucan suppressed tumor growth in nude mice bearing estrogen receptor-positive $(E R+)$ MCF-7 xenografts. The $\beta$-glucan exerted antiproliferative and apoptotic effects in MCF7 tumor tissues via pathways including caspase-, ERa-, ERK-, NF-KB-, PI3K/Akt/mTOR-, and p53-dependent pathways. Cleaved caspase-3, phosphorylated extracellular signal-regulated kinase 1/2 (p-ERK1/2), and poly [ADP (ribose)] polymerase 1 (PARP 1) tumor suppressor p53 protein levels were upregulated. In contrast, the expression of $\mathrm{B}$ cell lymphoma-2 (Bcl-2), estrogen receptor $\alpha(E R \alpha)$, nuclear factor-kappa $B(N F-k B) ~ p 65$, mouse double minute 2 (MDM2), telomerase reverse transcriptase (TERT), phosphorylated protein kinase B (p-Akt), phosphatidylinositol 3-kinase (PI3K), and mammalian target of rapamycin (mTOR) protein levels in tumor tissues was downregulated. Cell cycle was arrested at G2/M phase (Xu et al. 2017).

L. edodes polysaccharide lentinan had no effect on the growth, survival, and histamine sensitivity of adrenalectomized animals. Lentinan was also safe to advanced or recurrent breast cancer patients receiving bilateral oophorectomy and adrenalectomy, and prognosis of the patients was better after treatment (Kosaka et al. 1982). In patients with advanced or 
recurrent breast cancer as an agent receiving lentinan for supportive therapy, prolongation of life span was observed (Taguchi 1983).

Ten breast cancer patients were treated with cyclophosphamide, epirubicin, and 5-fluorouracil every 21 days for two cycles and then with $\mathrm{L}$. edodes mycelial extract during the second cycle. L. edodes mycelial extract prohibited the reduction in natural killer cell activity and leukocyte count (Nagashima et al. 2005). Three patients undergoing postoperative adjuvant chemotherapy for breast cancer underwent the first course of treatment (chemotherapy only) and the second course of treatment (chemotherapy plus concomitant administration of L. edodes mycelial extract). Enhancements in immunosuppressive acidic protein levels, activity of natural killer cells, and quality of life of patients were discernible only after the second course of combined therapy. No undesirable side effects were caused by administration of L. edodes mycelial extract (Yamaguchi et al. 2011). Twenty breast cancer patients received only estrogen-targeted hormone therapy during the first 4 weeks with no detectable alterations in the quality of life or cytokines. However, improvements were produced by combination treatment with hormone therapy and L. edodes mycelial extract in the subsequent 8 weeks (Suzuki et al. 2013). Aqueous extracts of L. edodes mycelial and fruit body extracts exerted antiproliferative and apoptotic actions on MCF-7 cells and proliferative actions on rat thymocytes in vitro and potentiated the proliferative actions of T mitogens on rat thymocytes in vitro (Israilides et al. 2008). The ethyl acetate fraction of $L$. edodes induced apoptosis in MCF7 and MDA-MB-453cancer cells via upregulating Bax and cdk inhibitor p21, downregulating cdk4 and cyclin D1, and bringing about cell cycle arrest (Fang et al. 2006).

L. edodes $\beta$-glucan suppressed tumor growth in nude mice bearing estrogen receptor-positive $(E R+)$ MCF-7 xenografts. The $\beta$-glucan exerted antiproliferative and apoptotic effects in MCF7 tumor tissues via pathways including caspase-, ERa-, ERK-, NF-kB-, PI3K/Akt/mTOR-, and p53-dependent pathways. Cleaved caspase-3, phosphorylated extracellular signal-regulated kinase1/2 (p-ERK1/2), and poly [ADP (ribose)] polymerase 1 (PARP 1) tumor suppressor p53protein levels were upregulated. The expression of $B$ cell lymphoma-2 $(\mathrm{Bcl}-2)$, estrogen receptor $\alpha(E R \alpha)$, nuclear factor-kappa $B(N F-k B)$ p65, mouse double minute 2 (MDM2), telomerase reverse transcriptase (TERT), phosphorylated protein kinase $B$ (p-Akt), phosphatidylinositol 3-kinase (PI3K), and mammalian target of rapamycin (mTOR) protein levels in tumor tissues was downregulated. Cell cycle was arrested at G2/M phase (Xu et al. 2017).

Lentinan had no effect on the growth, survival, and histamine sensitivity of adrenalectomized animals. Lentinan was also safe to advanced or recurrent breast cancer patients receiving bilateral oophorectomy and adrenalectomy, and prognosis of the patients was better after treatment (Kosaka et al. 1982). In patients with advanced or recurrent breast cancer as an agent receiving lentinan for supportive therapy, prolongation of life span was observed (Taguchi 1983).

Investigations on the action of lentinan in bettering the quality of life and augmenting the therapeutic efficacy of radiotherapy and chemotherapy performed in China from 2004 to 2016 included 183 cases of ovarian cancer, 15 cases of cardiac cancer, 130 cases of cervical cancer, 1646 cases of colorectal cancer, 1 case of duodenal cancer, 3039 cases of gastric cancer, 3469 cases of lung cancer, 14 cases of nasopharyngeal cancer, 70 cases of nonHodgkin lymphoma, and 15 cases of pancreatic cancer as searched from various databases. The studies revealed the efficacy of lentinan (Zhang et al. 2019b).

Lentinus polychrous 
Compounds isolated from the mycelia of the Thai mushroom L. polychrous, including 6methylheptane-1,2,3,4,5-pentaol and five ergostanoids, namely (22E,24R)-ergosta-7,22-dien$3 \beta, 5 \alpha, 6 \beta$-triol $3 \beta, 5 \alpha$-dihydroxy-(22E,24R)-ergosta-7,22-dien-6-one, $\quad$ ergosta-4,6,8(14),22tetraen-3-one, $\quad(3 \beta, 5 \alpha, 8 \alpha, 22 \mathrm{E})$-5,8-diepoxy-ergosta-6,22-dien-3-ol, and 5,8-epidioxy$(3 \beta, 5 \alpha, 8 \alpha, 22 \mathrm{E})$-ergosta-6,9(11),22-trien-3-ol, exhibited a repressive effect on proliferation of T47D breast cancer cells stimulated by estradiol. Among the various compounds, only ergosta4,6,8(14),22-tetraen-3-one demonstrated binding to estrogen receptors, with higher selectivity to estrogen receptor $\alpha$ than estrogen receptor- $\beta$. The other compounds expressed antiproliferative activity via mechanisms other than binding to estrogen receptors (Fangkrathok et al. 2013).

\section{Lepista inversa}

Extract of the Portuguese wild mushrooms Lepista inversa containing polysaccharides (obtained by boiling water extraction) and phenolic extracts (obtained by methanol and ethanol extraction) demonstrated suppressive activity on breast, colon, gastric, and lung cancer cells as well as antioxidant activity (Vaz et al. 2010).

\section{Lignosus rhinocerotis}

Alpha-cadinol[(1R,4S,4aR,8aR)-1,6-dimethyl-4-propan-2-yl-3,4,4a,7,8,8a-hexahydro-2Hnaphthalen-1-ol] and (+)-torreyol[(1S,4R,4aS,8aR)-1,6-dimethyl-4-propan-2-yl-3,4,4a,7,8,8ahexahydro-2H-naphthalen-1-ol] from Lignosus rhinocerotis demonstrated cytotoxicity to MCF7 cells with IC50 $=18.0 \pm 3.27 \mu \mathrm{g} / \mathrm{ml} \mathrm{IC50}$ value of $3.5 \pm 0.58 \mu \mathrm{g} / \mathrm{ml}$, while $\alpha$-cadinol was less active (Yap et al. 2017).

A cytotoxic a serine protease-like protein (F5) from sclerotia of the tiger milk mushroom Lignosus rhinocerotis (tiger milk mushroom), composed of $31-\mathrm{kDa}$ and $36-\mathrm{kDa}$ bands in reducing SDS-PAGE, was cytotoxic toward MCF7 cells with an IC50 value of $3.00 \mu \mathrm{g} / \mathrm{ml}$. The cytotoxicity was inhibitable by phenylmethylsulfonyl fluoride, a specific serine protease inhibitor (Yap et al. 2015). F5 increased the activities of caspase-8, caspase-9, Bax, BID, and cleaved BID and levels of Bcl-2 (Yap et al. 2018).

Rhinocelectin, 22.8-kDa recombinant homotetrameric lectin with a single alpha-helix and eleven beta-sheets, displayed IC50 values of $53.11,36.52$, and $142.19 \mu \mathrm{g} / \mathrm{ml}$, respectively, against MCF-7 and MDA-MB-231 triple-negative human breast cancer cells and 184B5 human nontumorigenic breast cells. Rhinocelectin treatment caused the breast cancer cells to stay in G0/G1 phase of the cell cycle and undergo apoptosis (Cheong et al. 2019).

Lyophyllum shimeji

The 14.5-kDa Lyophyllum shimeji ribonuclease suppressed proliferation of MCF7 cells with an IC50 of $6.2 \mu \mathrm{M}$ (Zhang et al. 2010a). An inhibitory action of the protein extract from Lyophyllum shimeji toward human oral squamous cell carcinoma (Jung et al. 2014) and ethyl acetate extract toward colorectal HCT-116 cells (Rossiana et al. 2018) has been reported.

\section{Marasmius oreades}

Two of the four chromatographic fractions in the culture liquid extract of Marasmius oreades repressed the phosphorylation of IkappaBalpha and NF-kappaB reporter activity in MCF7 cells. The two fractions impaired p65 nuclear translocation and inhibited the lkappaB kinase (IKK) activation pathway leading to NF-kappaB activation and apoptosis of MCF7 cells (Petrova et al. 2009). 
The ethanolic extract of M. oreades from Turkey exhibited a diversity of phenolics such as vanillic acid, gallic acid, ferulic acid, and catechin showed a moderate anticancer activity on MDA-MB-231 and MCF-7 cells (Shomali et al. 2019).

\section{Paecilomyces japonica}

Paecilomyces japonica agglutinin is an acidic sialic acid-specific $16-\mathrm{kDa}$ protein which expresses cytotoxicity toward MDA-MB-231 cells (Park et al. 2004).

Phellinus linteus

P. linteus extracts triggered, in triple-negative breast cancer cells, the appearance of autophagy hallmarks comprising autophagic vacuoles, acidic vesicular organelles, and autophagosome membrane association of microtubule-associated protein light chain 3 (LC3) indicating cleavage of LC3 and its punctuate redistribution. Synergism in suppressing growth of the breast cancer cells between the extracts and 5 -fluorouracil has been demonstrated ( $\mathrm{Li}$ et al. 2015). Hispolon [6-(3,4-dihydroxyphenyl)-4-hydroxyhexa-3,5-dien-2-one] from P. linteus suppressed ERa expression at both mRNA and protein levels, transcriptional activity of ERa, expression of ERa target gene pS2, and cell growth in T47D and MCF7 human breast cancer cells (Jang et al. 2015). The P. linteus fraction PL-ES exerted antiproliferative activity on ten types of cancer cells including breast cancer cells resulting in apoptosis (Konno et al. 2015).

Pholiota adiposa

The homodimeric 32-kDa Pholiota adiposa lectin showed antiproliferative activity toward MCF7 cells with an IC50 in the vicinity of $3.2 \mu \mathrm{M}$ (Zhang et al. 2009b).

Pholiota nameko

A $18.5-\mathrm{kDa}$ antitumor protein from Pholiota nameko with the $\mathrm{N}$-terminal sequence AGRTFIGYNG demonstrated antiproliferative activity against a variety of cancer cell lines such as MCF7 cells. Cells exposed to the protein exhibited a plethora of hallmarks of apoptosis such as condensation of chromatin, arrest of cells in the sub-G1 phase of the cell cycle, mitochondrial membrane permeabilization, membrane potential disruption, and liberation of cytochrome $c$ into the cytoplasm, caspase -3 and caspase- 9 activation, culminating in the triggering of apoptosis (Zhang et al. 2014). Another protein from Pholiota nameko, with a molecular weight of $43 \mathrm{kDa}$, disrupted mitochondrial transmembrane potential, altered distribution of cells in different phases of the cell cycle, and exhibited antiproliferative and apoptosis-inducing activities toward MCF7 cells (Qian et al. 2016).

\section{Pleurotus abalonus}

Pleurotus abalonus polysaccharide was composed of arabinose, galactose, glucose, glucuronic acid, rhamnose, and xylose, in the molar ratio of 1.2:1.8:26.3:1:2.7:1.4. The polysaccharide with antioxidant and radical scavenging activities manifested antiproliferative activity toward breast cancer MCF7 cells with an IC50 of $3.7 \mu \mathrm{M}$ (Wang et al. 2011). PAP-3, the 368-kDa P. abalonus acidic polysaccharide, exhibited antiproliferative activity toward MCF7 cells with an IC50 of $193 \mu \mathrm{g} / \mathrm{ml}$. Disruption of mitochondrial membrane potential, degradation of poly (ADP-ribose) polymerase, arrest of cells in the $S$ phase of the cell cycle, rise in Bax/Bcl2 ratio, activation of caspase- $3 / 9$ and p53, and increase in intracellular reactive oxygen species production occurred in MCF-7 cells after exposure to the polysaccharide. $\mathrm{N}$-acetylcysteine and superoxide dismutase impaired reactive oxygen species formation and apoptosis in MCF-7 cells caused by PAP-3, signifying that intracellular reactive oxygen species is implicated in apoptosis (Shi et al. 2013). 
PAP-3, the368-kDa P. abalonus acidic polysaccharide, exhibited antiproliferative activity toward MCF-7 cells with an IC50 of $193 \mu \mathrm{g} / \mathrm{ml}$. Disruption of mitochondrial membrane potential, degradation of poly (ADP-ribose) polymerase, arrest of cells in the S phase of the cell cycle, rise in Bax/Bcl-2 ratio, activation of caspase- $3 / 9$ and $\mathrm{p} 53$, and increase in intracellular reactive oxygen species production occurred in MCF-7 cells after exposure to the polysaccharide. $\mathrm{N}$ acetylcysteine and superoxide dismutase impaired reactive oxygen species formation and apoptosis in MCF-7 cells caused by PAP-3, signifying that intracellular reactive oxygen species is implicated in apoptosis (Shi et al. 2013).

Pleurotus eryngii

A polypeptide from Pleurotus eryngii mycelia manifested free radical scavenging activity and antiproliferative activity toward breast cancer cells, but proliferative activity toward macrophages. It enhanced secretion of interleukin- 6 and tumor necrosis factor- $\alpha$, Toll-like receptor 2, and Toll-like receptor 4 expression and stimulated phagocytosis of macrophages (Sun et al. 2017).

Pleurotus geesteranus

PG-2 from Pleurotus geesteranus, a homopolysaccharide essentially consisting of glucose, expressed cytotoxicity to human breast cancer cells (Zhang et al. 2011).

Pleurotus highking

Fraction-III PEF-III derived from Pleurotus highking extract triggered apoptosis of MCF-7 cells as evidenced by DNA laddering, annexin V phycoerythrin, and propidium iodide staining, downregulation of the antiapoptotic gene $\mathrm{Bcl} 2$, and upregulation of the pro-apoptotic genes p53 and Bax and the enzymes caspase-3 and caspase-7 (Haque and Islam 2019).

Pleurotus nebrodensis

The fungal sterol ergosterol, among nine compounds isolated from the acetic ether extract of Pleurotus nebrodensis, manifested an IC50 concentration of $112.65 \mu \mathrm{mol} / \mathrm{l}$ toward MCF-7 cells. Ergosterol arrested MCF-7 cells in S phase of the cell cycle and triggered apoptosis (Hao et al. 2017).

Pleurotus ostreatus

P. ostreatus extracts exerted antiproliferative activity toward MCF-7 and MDA-MB-231 cells but not epithelial mammary MCF-10A cells. The cells were arrested at G0/G1 phase of the cell cycle. Expression of the cyclin-dependent kinase inhibitor p21 and tumor suppressor p53 was upregulated. In contrast, phosphorylation of retinoblastoma $\mathrm{Rb}$ protein was undermined (Jedinak and Sliva 2008). The ethanolic extract of Pleurotus ostreatus containing ergosterol, at a dose of $600 \mathrm{mg} / \mathrm{kg}$, reversed the attenuated levels of enzymatic and non-enzymatic antioxidants and heightened levels of TBARS in hepatic tissues, mammary glands, and blood of rats treated with the carcinogen 7,12-dimethylbenz(a)antheracene which produced mammary cancer (Krishnamoorthy and Sankaran 2016).

The 6-linked glucans in P. ostreatus extracts potentiated the cytotoxic activity of natural killer cells against breast and lung cancer cells, which was associated with NKG2D gene upregulation, via regulation of induction of nitric oxide and interferon- $\gamma$ which was associated with KIR2DL gene upregulation. The cytotoxicity was augmented by interleukin-2 (El-Deeb et al. 2019).

Podostroma cornu-damae 
Compounds 4, 6, and 8 isolated from the methanolic extract of the toxic mushroom P. cornudamae demonstrated IC50 values (0.02-80 nM) against MDA-MB-468, MDA-MB-231, HCC70, and Bt549 human breast cancer cells (Lee et al., 2019a).

\section{Poria cocos}

A water-soluble beta-glucan PCM3-II from Poria cocos demonstrated antiproliferative activity and diminished viability of MCF-7 cells, attenuated expression of cyclin D1 and cyclin E; arrested the cells at $\mathrm{G} 1$ phase of the cell cycle, raised the $\mathrm{Bax} / \mathrm{Bcl}-2$ ratio, and triggered apoptosis by downregulating Bcl-2 without affecting Bax (Zhang et al. 2006). Oral solution of Poria cocos polysaccharide has been available as a health supplement for more than three decades. The Chinese Food and Drug Administration gave approval in 2015 to oral solution of Poria cocos polysaccharide as an anticancer drug. The various investigations on Poria cocos polysaccharide from 1970 to 2016 recorded in the different databases were reviewed by Li et al. (2019).

\section{Russula delica}

The dimeric 60-kDa Russula delica lectin demonstrated antiproliferative activity toward MCF7 cells, with an IC50 value of $0.52 \mu \mathrm{M}$ (Zhao et al. 2010).

Russula lepida

The 32-kDa Russula lepida lectin exhibited antiproliferative activity toward MCF-7 cells with an IC50 of $0.9 \mu \mathrm{M}$ (Zhang et al. 2010b).

\section{Sarcodon imbricatus}

Inflammation plays a critical part in tumorigenesis and metastatic spread. Cytokines have inductive as well as protective roles in mammary carcinogenesis (Esquivel-Velázquez et al. 2015). A water extract of $S$. imbricatus exerted a suppressive action on the in vitro proliferation, migration, and invasiveness of breast cancer cells and in vivo tumor enlargement. The circulating levels of tumor necrosis factor- $\alpha$, interleukin- 6 , and interleukin-2, activity of natural killer cells, and splenocyte viability were upregulated. In contrast, programmed cell deathligand 1 (PD-L1) expression in 4T1 tumor-bearing mice was downregulated (Tan X, et al., 2019).

\section{Schizophyllum commune}

Schizophyllan and tamoxifen curtailed the incidence of mammary tumors induced by dimethylbenz( $\alpha$ )anthracene by $85 \%$ and $75 \%$, respectively, and depressed the proliferating cell nuclear antigen labeling index relative to dimethylbenz( $\alpha$ )anthracene (Mansour et al. 2012). Following exposure to ultrasound, the immunopotentiating action of schizophyllan toward splenic lymphocytes and RAW264.7 macrophages and antiproliferative action of schizophyllan toward human breast carcinoma T-47D cells was escalated (Zhong et al. 2015).

Trametes robiniophila

Huaier polysaccharide from the mushroom $T$. robiniophila has been extensively utilized clinically in cancer therapy in China. It acted against breast cancer stem cells which account for the aggressiveness in triple-negative breast cancer cells, inhibiting production of mammospheres, stem-related gene expression in vitro and xenograft tumorigenesis in vivo, estrogen receptor $\alpha-36$ (ERa-36) expression, and upregulation of the AKT/ $\beta$-catenin signaling mediated by the receptor in ERa-36high triple-negative breast cancer cells (Hu et al. 2019).

Tricholoma mongolicum 
A 66-kDa laccase from $\mathrm{T}$. mongolicum with the $\mathrm{N}$-terminal amino acid sequence GIGPVADLYVGNRIL exhibited antiproliferative activity toward breast cancer MCF7 cells with an IC50 of $4.2 \mu \mathrm{M}$ ( $\mathrm{Li}$ et al., 2010a). The fourth fraction purified from T. mongolicum crude polysaccharides exhibited the highest antiproliferative and antioxidant activities (Li et al. 2015).

Xylaria psidii

5-Methylmellein [3R)-8-hydroxy-3, 5-dimethyl-3, 4-dihydroisochromen-1-one] (from X. psidii)loaded bovine serum albumin nanoparticles showed higher cytotoxicity and apoptosis-inducing activity against MCF-7 cells than 5-methylmellein (Arora et al. 2017).

Xylaria schweinitzii

Schweinitzins $A$ and (S)-torosachrysone-8-O-methyl ether from methanolic extract of $X$. schweinitzii fruiting bodies demonstrated potent cytotoxic action against several types of human cancer cells including MCF7 (breast cancer), HepG2 (liver cancer), SK-LU-I (lung cancer), and KB (epidermal cancer) cells (Linh et al. 2014).

Xylaria sp. R006

Fraction $\mathrm{E}$ derived from the ethyl acetate extract of fruiting bodies of Xylaria sp. R006 was active against MCF-7 and MDA-MB-231 cells (Ramesh et al. 2015).

\section{Conclusion}

HER2-positive breast cancer which is highly malignant makes up one fifth to one quarter of all breast cancers. Trastuzumab therapy for 1 year is a standard treatment since prolonging the duration only raises the incidence of cardiotoxicity, whereas reducing the duration is not beneficial trastuzumab and pertuzumab plus chemotherapy represents the present standard of first-line treatment for HER2-positive malignant breast cancer. Trastuzumab emtansine (TDM1) and small-molecule TKI are used for the second-line and third-line treatments, respectively. Nevertheless, there may be a total lack of response or drug resistance to lapatinib, neratinib, pertuzumab, and trastuzumab. Future investigations should be encouraged to explore new clinical trial approaches using new drugs, in particular research at the gene level. The HER2 detection techniques should be improved to enhance the accuracy of results. The genes regulating breast cancer cell proliferation and metastasis as well as the prognostic factors should be identified (Wang and $\mathrm{Xu}$ 2019). Monoclonal antibodies, like pertuzumab and trastuzumab, demonstrate efficacy against human epidermal growth factor receptor 2-positive cancer. Nevertheless, they are expensive and there are side effects (Zurrida and Veronesi 2015). There are no specific standard therapeutic rules to follow for elderly breast cancer patients. Surgery did not have a predictive value for survival in invasive breast cancer patients with an age beyond 80 (Ferrigni et al. 2019). Although preliminary results are available, more work is necessitated before mobile apps can be employed for primary prevention of breast cancer (Houghton et al. 2019).

Precision medicine for metastatic breast cancer sounds attractive but practicing it clinically is difficult. Bioinformatic tools may facilitate identification of driver mutations which lead to breast cancer. Ultra-deep sequencing and circulating tumor DNA measurements may facilitate detection of the genetic causes of resistance early. In view of the low incidence of the majority of candidate mutations which impedes randomized trials, screening of many more patients, clustering of gene mutations into pathways, and personalized medicine trials will be required (Arnedos et al. 2015).

Over 100 renowned scientific investigators and physicians reached a consensus several years ago regarding the existence of ten gaps in breast cancer research as follows: (1) 
comprehending the functions and interactions of genetic and epigenetic modifications in normal breast development and carcinogenesis; (2) bringing about modifications in lifestyle (diet, exercise, and body weight) and anticancer approaches; (3) requirement for tailored screening methodology; (4) upgrading understanding of molecular mechanisms behind various subtypes, progression and metastatic spread of breast cancer; (5) understanding the molecular mechanisms of tumor heterogeneity, dormancy, de novo or acquired resistance, and how to target key nodes in these dynamic processes; (6) developing markers for sensitivity to chemotherapy and radiotherapy; (7) ascertaining the most appropriate time length, order, and combinations of therapy for ameliorated personalized treatment; (8) validating imaging biomarkers with diverse modalities for minimally invasive diagnosis and ascertaining efficacy of treatment in primary and metastatic breast cancer; (9) providing assistance and support to the survivors experience; and (10) requirement for normal breast samples and samples from patients at different disease stages for translational research with assistance from bioinformatics (Eccles et al. 2013). Cutress et al. (2018) authored a review which added to the 2013 Breast Cancer Campaign gap analysis. The main research gaps in breast surgery comprised issues regarding overdiagnosis and therapy; optimizing therapeutic measures such as chemotherapy, radiation therapy, and hormone therapy to reduce tumor size prior to surgery; minimizing need of operations again for breast-conserving surgery; producing proof for clinical efficacy and cost-effectiveness of breast plastic surgery and mechanisms for evaluating new procedures; and devising the best axillary management, in particular following chemotherapy, radiation therapy, and hormone therapy to reduce tumor size. Surgeons should promote an atmosphere of involvement in research for the benefit of patients as well as healthcare organizations. A strong research capability and adequate funding to support research are necessary.

Cardoso et al. (2017) gave an account of the 12 most urgently needed research areas for clinical research in breast cancer proposed in 2016 by experts (i) reduce breast cancer treatments in early breast cancer patients without adversely affecting the results; (ii) ascertain the most appropriate time length for adjuvant therapy; (iii) design improved devices and approaches to distinguish genetically predisposed patients; (iv) upgrade care in young breast cancer patients; ( $v$ ) design devices to accelerate drug development in populations which are biomarker-defined; (vi) ascertain and validate targets implicated in recalcitrance to chemotherapy, hormonal treatment, and anti-HER2 treatment; (vii) assess the effectiveness of local-regional therapy for metastatic breast cancer; (viii) better define the most appropriate therapeutic sequence in metastatic breast cancer; (ix) assess the importance of intratumor, intertumor, and interlesion heterogeneity in a patient; $(\mathrm{x})$ better comprehend the biology and ascertain novel targets in triple-negative breast cancer; (xi) better comprehend immunological surveillance in breast cancer and exploit the immune system for cancer therapy; and (xii) intensify investigations on survivors regarding supportive care and quality of life.

Applications of cancer stem cells in breast cancer therapy encompass targeting surfacespecific markers and activated signaling pathways in the microenvironment, such as BMP, Hedgehog, NF-kB, Notch, PI3K/AktTGF- $\beta$, and Wnt/b-catenin, and their maintenance and drug resistance, by employing miRNAs, triggering apoptotic death of cancer stem cells, differentiation treatment, and preventing epithelial-to-mesenchymal transition (Ghasemi et al. 2019). The relationship between occupation and breast cancer can be ascertained by collecting data on age at diagnosis of breast cancer, characteristics of breast cancer, demographic characteristics, status of menopause, risk factors, history of occupations, work environment, and exposures. It would help to involve workers in the research on their own occupational risks and exposures (Engel et al. 2018). 
Interdisciplinary cooperation among scientific researchers, clinical investigators, healthcare organizations, and government will hopefully decrease the death rate caused by breast cancer (Partridge and Carey 2017).

In view of the aforementioned limitations regarding breast cancer therapy, the intent of this review was to examine the value of mushroom extracts and compounds as dietary supplements and alternative therapeutics for breast cancer. The anticancer constituents from different mushrooms are structurally diverse and differ considerably in molecular weight. There are compounds such as brefeldin A from A. blazei (Dong et al. 2013); panepoxydone from L. critinus (Arora et al. 2014); ergosterol, ergosterol peroxide, and 5, 6-dehydroergosterol from G. lucidum (Martínez-Montemayor et al. 2019). Besides these compounds, there are proteins such as a 68-kDa laccase from A. placomyces (Sun et al. 2012), a 12-kDa antifungal protease (Park et al. 2004), a 10.9-kDa antifungal peptide cordymin (Wong et al. 2011) from C. militaris and a 9.5-kDa ribosome inactivating protein marmorin from $\mathrm{H}$. marmoreus (Wong et al. 2008), a 14.5-kDa ribonuclease from $\mathrm{L}$. shimeji (Zhang et al. 2010a), a 66-kDa laccase from T. mongolicum ( $\mathrm{Li}$ et al. 2010b), and a dimeric 60-kDa lectin from R. delica (Zhao et al. 2010). There are polysaccharides such as $368-\mathrm{kDa} \mathrm{P}$. abalonus acidic polysaccharide (Shi et al. 2013) and schizophyllan with a molecular weight of $450 \mathrm{kDa}$ and C. versicolor PSP with a molecular weight exceeding $100 \mathrm{kDa}(\mathrm{Ng}$ 1998). There may be a multiplicity of anticancer substances in a mushroom species: in addition to ergosterol and ergosterol derivatives, there are ganoderic acids (Jiang et al. 2011; Wu et al. 2012a; Yang et al. 2018). Some mushroom proteins are protease-resistant and/or pH-stable (Huang et al. 2011; Hu et al. 2017). Some lectins are protease-stable (Gabor et al. 1997; Zhu-Salzman et al. 2002; Clement and Venkatesh 2010) and it is likely that some of the mushroom lectins have a similar attribute. It has already been noted that a diet rich in mushrooms is good for preventing breast cancer (Hong et al. 2008; Zhang et al. 2009a; Shin et al. 2010). The anticancer activity may be attributed to nonproteinaceous as well as protease-stable and/or proteinaceous constituents.

Medicinal mushrooms most commonly used for breast cancer patients include C. sinensis, Ganoderma lucidum, and C. versicolor. Of all aforementioned mushrooms, it appears that C. versicolor yields the best results and can be used not only in the therapy of breast cancer but also for other cancers because of the following reasons: C. versicolor has been used as a traditional mushroom in China for over two millennia. C. versicolor PSK and PSP have been in routine clinical practice in Japan since 1977 and in China since 1987, respectively. PSP contributes to prolonging survival and bettering the quality of life, not only in cancer patients but also in patients afflicted with hepatitis, hyperlipidemia, and other chronic diseases. The results of an analysis of over 40 independent PSP-related preclinical and clinical studies conducted in China during the last four decades based on searches of the Chinese VIP, CNKI, and Wanfang databases lend credence to the utilization of Yunzhi as an immunotherapeutic adjuvant (Chang et al. 2017b). PSP produces direct tumor suppressing effects. It has been proven to trigger apoptosis of cancer cells through a diversity of mechanisms (Lau et al. 2004; Ho et al. 2004a, 2005, 2006) especially via its an anti-telomerase effect (Kenyon). PSP undermines induction of growth of peripheral blood vessels (angiogenesis) by tumor cells. Such repression will diminish blood supply to tumor cells, thus significantly thwarting the otherwise rapid growth of tumor cells (Ho et al. 2004b). PSP prolongs the duration required for cancer cell multiplication thus attenuating growth of cancer cells. PSP exerts a direct antiproliferative action on a broad spectrum of tumor cell lines, including leukemia cells, liver cancer cells, and cervical cancer cells, etc. (Lau et al. 2004; Ho et al. 2004a, 2005, 2006; Chang et al. 2017a).

PSP elicits immunotherapeutic effects to battle against tumors and infections of cancer patients by heightening production of chemokines and cytokines (Saleh et al. 2017) by 
stimulating production of white blood cells such as B cells and accelerates transformation of $T$ cells (Saleh et al. 2017), by raising levels of interferon-gamma and tumor necrosis factor-alpha, as well as enhances activity of natural killer cells, macrophages, and the complement system (Saleh et al. 2017), and by upregulating the expression of surface antigen of cancer cells hence facilitating the immune system to recognize and annihilate the cancer cells (Chang et al. 2017b; Saleh et al. 2017). PSP exerts protective effects on the brain and liver, allowing cancer patients to lead a longer and better life (Fang et al. 2015; Trovato Salinaro et al. 2018; Wang et al., 2019). PSP mitigates pain sensation enabling patients to enjoy a better quality of life ( $\mathrm{Ng}$ and Chan 1997; Gong et al. 1998). PSP exerts direct bacteriostatic and virustatic effects: it directly suppresses growth of many bacteria and viruses (Palacios et al. 2017; Rodríguez-Valentín et al. 2018). PSP augments the effects of anticancer drugs. It has been proven to potentiate efficacy of some drugs, e.g., doxorubicin (Saleh et al. 2017). PSP manifests antioxidant effect: it reinforces antioxidant defense of cancer patients and better equips them to combat cancer (Sun et al. 2014). PSP prolongs and elevates survival rate of cancer patients (Saleh et al. 2017). PSP prevents primary tumor from forming and forestalls secondary metastasis of tumor cells. It curbs the growth of xenografts derived from tumor cells (gastric cancer, liver cancer, prostatic cancer, nasopharyngeal carcinoma, and lung adenocarcinoma, etc.) inoculated into nude mice (Ho et al. 2004b; Chang et al. 2017a). It directly inhibits aflatoxin B induction of liver cancer in animals (Scarpari et al. 2016). PSP prevents aggressive metastatic cancer cells from invading other tissues and organs (Luo et al. 2014). PSP reduces deleterious side effects of cancer therapy. Addition of PSP to radiotherapeutic or chemotherapeutic protocols can greatly uplift the quality of life of cancer patients. PSP alleviates chemotherapy-induced side effects including weakness, inappetence, vomiting, dryness of throat, spontaneous sweating, and pain symptoms (Kidd 2000). PSP elicits minimal herb-drug interaction. The relatively high Ki (inhibitor constant) values of PSP toward three different human cytochrome P450 enzymes (CYP2C9, CYP1A2, and CYP3A4), which are drug-metabolizing enzymes, signify only a low potential of PSP to elicit herb-drug interaction (Yeung and Or 2011, 2012).

This article reviews mushrooms with anti-breast cancer activity. The mushrooms include the following: button mushroom Agaricus bisporus, Brazilian mushroom A. blazei, A. placomyces, wood mouse mushroom A. sylvaticus, Amauroderma rude, Amauroderma rugosum, stout camphor fungus Antrodia camphorata, Antrodia salmonea, Jew's ear (black) fungus or black woodear fungus Auricularia auricula-judae, Clitocybe alexandri, Coprinellus sp., shaggy ink cap Coprinus comatus, hoof fungus Fomes fomentarius, agarikon Fomitopsis officinalis, reishi mushroom or Lingzhi Ganoderma atrum, G. lipsiense, G. lipsiense, G. lucidum (reishi mushroom, Lingzhi), G. resinaceumn, G. sinense, Hemlock varnish shelf $G$. tsugae, maitake mushroom or sheep's head mushroom Grifola frondosa, lion's mane mushroom or monkey head mushroom Hericium erinaceum, brown beech mushroom Hypsizigus marmoreus, chaga mushroom Inonotus obliquus, sulfur polypore mushroom Laetiporus sulphureus, Lentinus crinitus, Lentinula edodes(shiitake mushroom), Lentinus polychrous, tawny funnel cap Lepista inversa, tiger milk mushroom Lignosus rhinocerotis, Marasmius oreades, Lyophyllum shimeji, Paecilomyces japonica, Phellinus linteus (Japanese "meshimakobu," Chinese "song gen," Korean "sanghwang," English "Meshima," American English "black hoof mushroom") Pholiota adiposa, butterscotch mushroom Pholiota nameko, abalone mushroom Pleurotus abalonus, king oyster mushroom Pleurotus eryngii, Pleurotus geesteranus, Pleurotus nebrodensis, oyster mushroom Pleurotus ostreatus, tuckahoe or Fu Ling Poria cocos, Russula delica, Russula lepida, split gill mushroom Schizophyllum commune, Tricholoma mongolicum, Xylaria psidii, Xylaria schweinitzii, and Xylaria sp. R006 (Table 1).

Table 1 Mushroom extracts and purified constituents with inhibitory activity on cultured breast cancer cells $(\mathrm{CC})$, tumor-bearing animals $(\mathrm{A})$, or human trials $(\mathrm{HT})$ 


\section{Full size table}

This review disclosed that among the many investigations showing a suppressive action of various mushrooms on breast cancer, in vivo demonstrations of the anticancer efficacy using tumor-bearing mice are available only for the following mushroom species. They comprise Agaricus bisporus, Amaurodema rude, Antrodia salmonea, Cordyceps sinensis, C. militaris, Coriolus versicolor, Ganoderma lucidum, G. sinense, Grifola frondosa, Hypsizygus marmoreus, and Lentinula edodes. Demonstrations of the antineoplastic effectiveness in human clinical trials have been reported only for Agaricus sylvaticus, Antrodia camphorata, Cordyceps sinensis, Coriolus versicolor, Ganoderma lucidum, Grifola frondosa, and Lentinula edodes which are the better-known mushrooms. Mechanistic studies on the anticancer action of various mushrooms on breast cancer were only conducted on the following mushroom species. The list of mushrooms includes Amaurodema rude, Antrodia camphorata, Cordyceps sinensis, C. militaris, Coriolus versicolor, Ganoderma lucidum, Grifola frondosa, Hypsizygus marmoreus, Lentinus critinus, Lentinula edodes, Pholiota nameko, Pleurotus abalonus, Pleurotus eryngii, Pleurotus nebrodensis, Pleurotus ostreatus, and Poria cocos. It was revealed that dissimilar mechanistic results might be obtained for the same mushroom extract or constituent since molecules on different signaling pathways were examined by different investigators (Table 2). It would be desirable to conduct in vivo experiments using purified mushroom constituents in order to corroborate in vitro results on inhibition of breast cancer cells by mushroom extracts. Mechanistic investigations should also be undertaken. In this way, mushroom constituents with high anticancer potency may be discovered. Compounds from medicinal mushrooms and culinary-medicinal mushrooms have the potential of development into anticancer drugs (Wong et al. 2018).

Table 2 The range of signaling molecules associated with various pathways employed by selected mushroom species examined in different studies

Full size table

Dietary consumption of mushrooms is associated with a diminished risk of breast cancer (Hong et al. 2008; Zhang et al. 2009b; Shin et al. 2010). The use of mushroom extracts or compounds as adjunct therapeutics may enhance the efficacy of the main therapy. There are different mushroom products. For instance, the medicinal product five-color Lingzhi (Vita Green) is composed of Amauroderma rugosum (black Lingzhi), Coriolus versicolor (green Lingzhi), Fomitopsis officinalis (white Lingzhi), Ganoderma lucidum (red Lingzhi), Ganoderma sinense (purple Lingzhi), and Laetiporus sulphureus (yellow Lingzhi). It is worthwhile to consume mushrooms to protect ourselves from breast cancer, other cancers, and other diseases (Dubey et al. 2019).

\section{References}

1. Acevedo-Díaz A, Ortiz-Soto G, Suárez-Arroyo IJ, Zayas-Santiago A, Martínez Montemayor MM (2019) Ganoderma lucidum extract reduces the motility of breast cancer cells mediated by the RAC-lamellipodin axis. Nutrients 11(5):E1116. https://doi.org/10.3390/nu11051116

\section{CAS PubMed Article Google Scholar}

2. Alonso EN, Orozco M, Eloy Nieto A, Balogh GA (2013) Genes related to suppression of malignant phenotype induced by Maitake D-Fraction in breast cancer cells. J Med Food 16(7):602-617. https://doi.org/10.1089/jmf.2012.0222

PubMed PubMed Central Article Google Scholar 
3. Alonso EN, Ferronato MJ, Gandini NA, Fermento ME, Obiol DJ, López Romero A, Arévalo J, Villegas ME, Facchinetti MM, Curino AC (2017) Antitumoral effects of D-fraction from Grifola Frondosa (maitake) mushroom in breast cancer. Nutr Cancer 69(1):29-43. https://doi.org/10.1080/01635581.2017.1247891

4. Alonso EN, Ferronato MJ, Fermento ME, Gandini NA, Romero AL, Guevara JA, Facchinetti MM, Curino AC (2018) Antitumoral and antimetastatic activity of Maitake DFraction in triple-negative breast cancer cells. Oncotarget 9(34):23396-23412. https://doi.org/10.18632/oncotarget.25174

PubMed PubMed Central Article Google Scholar

5. Aoyagi H, lino Y, Takeo T, Horii Y, Morishita Y, Horiuchi R (1997) Effects of OK-432 (picibanil) on the estrogen receptors of MCF-7 cells and potentiation of antiproliferative effects of tamoxifen in combination with OK-432. Oncology 54(5):414-423. https://doi.org/10.1159/000227728

CAS PubMed Article Google Scholar

6. Arnedos M, Vicier C, Loi S, Lefebvre C, Michiels S, Bonnefoi H, Andre F (2015) Precision medicine for metastatic breast cancer-limitations and solutions. Nat Rev Clin Oncol 12(12):693-704. https://doi.org/10.1038/nrclinonc.2015.123

CAS PubMed Article Google Scholar

7. Arora R, Yates C, Gary BD, McClellan S, Tan M, Xi Y, Reed E, Piazza GA, Owen LB, Dean-Colomb W (2014) Panepoxydone targets NF-kB and FOXM1 to inhibit proliferation, induce apoptosis and reverse epithelial to mesenchymal transition in breast cancer. PLoS One 9(6):e98370. https://doi.org/10.1371/journal.pone.0098370

CAS PubMed PubMed Central Article Google Scholar

8. Arora D, Kumar A, Gupta P, Chashoo G, Jaglan S (2017) Preparation, characterization and cytotoxic evaluation of bovine serum albumin nanoparticles encapsulating 5methylmellein: a secondary metabolite isolated from Xylaria psidii. Bioorg Med Chem Lett 27(23):5126-5130. https://doi.org/10.1016/j.bmcl.2017.10.064

CAS PubMed Article Google Scholar

9. Asaishi K, Okazaki M, Hayasaka H (1988) Local treatment of locally recurrent breast cancers. Gan To Kagaku Ryoho 15(4 Pt 2-2):1325-1330

CAS PubMed Google Scholar

10. Asatiani MD, Wasser SP, Nevo E, Ruimi N, Mahajna J, Reznick AZ (2011) The Shaggy Inc Cap medicinal mushroom, Coprinus comatus (O.F.Mull. Fr.) Pers. (Agaricomycetideae) substances interfere with $\mathrm{H} 2 \mathrm{O} 2$ induction of the NF-kappaB pathway through inhibition of Ikappaalpha phosphorylation in MCF7 breast cancer cells. Int J Med Mushrooms 13(1):19-25. https://doi.org/10.1615/intjmedmushr.v13.i1.30

PubMed Article Google Scholar

11. Barbieri A, Quagliariello V, Del Vecchio V, Falco M, Luciano A, Amruthraj NJ, Nasti G, Ottaiano A, Berretta M, laffaioli RV, Arra C (2017) Anticancer and anti-Inflammatory properties of Ganoderma lucidum extract effects on melanoma and triple-negative breast cancer treatment. Nutrients 9(3):E210. https://doi.org/10.3390/nu9030210 
CAS PubMed Article Google Scholar

12. Bray F, Ferlay J, Soerjomataram I, Siegel RL, Torre LA, Jemal A (2018) Global cancer statistics 2018: GLOBOCAN estimates of incidence and mortality worldwide for 36 cancers in 185 countries. CA Cancer J Clin 68(6):394-424

Article Google Scholar

13. Cai H, Li J, Gu B, Xiao Y, Chen R, Liu X, Xie X, Cao L (2018) Extracts of Cordyceps sinensis inhibit breast cancer cell metastasis via down-regulation of metastasis-related cytokines expression. $\mathrm{J}$ Ethnopharmacol 214:106-112. https://doi.org/10.1016/j.jep.2017.12.012

\section{CAS PubMed Article Google Scholar}

14. Cardoso F, Harbeck N, Barrios C, Bergh J, Cortés J, El Saghir N, Francis PA, Hudis CA, Ohno S, Partridge AH (2017) Research needs in breast cancer. Ann Oncol 28(2):208217. https://doi.org/10.1093/annonc/mdw571

CAS PubMed Article Google Scholar

15. Chan HHL (2009) Formulation and use of ergosta-7, 22-dien-3beta-ol. Patent US2009247497 A1.

16. Chan JS, Asatiani MD, Sharvit LE, Trabelcy B, Barseghyan GS, Wasser SP (2015) Chemical composition and medicinal value of the new Ganoderma tsugae var. jannieae CBS120304 medicinal higher basidiomycete mushroom. Int J Med Mushrooms 17(8):735-747. https://doi.org/10.1615/intjmedmushrooms.v17.i8.40

\section{PubMed Article Google Scholar}

17. Chang YC, Hsiao YM, Wu MF, Ou CC, Lin YW, Lue KH, Ko JL (2013) Interruption of lung cancer cell migration and proliferation by fungal immunomodulatory protein FIP-fve from Flammulina velutipes. J Agric Food Chem 61(49):12044-12052. https://doi.org/10.1021/jf4030272

\section{CAS PubMed Article Google Scholar}

18. Chang CT, Hseu YC, Thiyagarajan V, Huang HC, Hsu LS, Huang PJ, Liu JY, Liao JW, Yang HL (2017a) Antrodia salmonea induces G (2) cell-cycle arrest in human triple-negative breast cancer (MDA-MB-231) cells and suppresses tumor growth in athymic nude mice. J Ethnopharmacol 196:9-19. https://doi.org/10.1016/j.jep.2016.12.018

19. Chang Y, Zhang M, Jiang Y, Liu Y, Luo H, Hao C, Zeng P, Zhang L (2017b) Preclinical and clinical studies of Coriolus versicolor polysaccharopeptide as an immunotherapeutic in China. Discov Med 23(127):207-219

PubMed Google Scholar

20. Chen S, Oh SR, Phung S, Hur G, Ye JJ, Kwok SL, Shrode GE, Belury M, Adams LS, Williams D (2006) Anti-aromatase activity of phytochemicals in white button mushrooms (Agaricus bisporus). Cancer Res 66(24):12026-12034. https://doi.org/10.1158/00085472.CAN-06-2206

CAS PubMed Article Google Scholar 
21. Chen GT, Fu YX, Yang WJ, Hu QH, Zhao LY (2018) Effects of polysaccharides from the base of Flammulina velutipes stipe on growth of murine RAW264.7, B16F10 and L929 cells. Int J Biol Macromol 107(Pt B):2150-2156

\section{CAS PubMed Article Google Scholar}

22. Chen JH, Wu THA, Tzeng DTW, Huang CC, Tzeng YM, Chao TY (2019a) Antrocin, a bioactive component from Antrodia cinnamomea, suppresses breast carcinogenesis and stemness via downregulation of $\beta$-catenin/Notch1/Akt signaling. Phytomedicine. 52:70-78. https://doi.org/10.1016/j.phymed.2018.09.213

23. Chen YC, Liu YC, El-Shazly M, Wu TY, Chang JG, Wu YC (2019b) Antrodia cinnamomea, a treasured medicinal mushroom, induces growth arrest in breast cancer cells, T47D cells: new mechanisms emerge. Int $J$ Mol Sci 20(4):E833. https://doi.org/10.3390/ijms20040833

CAS PubMed Article Google Scholar

24. Cheong PCH, Yong YS, Fatima A, Ng ST, Tan CS, Kong BH, Tan NH, Rajarajeswaran J, Fung SY (2019) Cloning, overexpression, purification, and modeling of a lectin (Rhinocelectin) with antiproliferative activity from tiger milk mushroom, Lignosus rhinocerus. IUBMB Life 71(10):1579-1594. https://doi.org/10.1002/iub.2101

25. Choi S, Lim MH, Kim KM, Jeon BH, Song WO, Kim TW (2011) Cordycepin-induced apoptosis and autophagy in breast cancer cells are independent of the estrogen receptor. Toxicol A ppl Pharmacol 257(2):165-173. https://doi.org/10.1016/j.taap.2011.08.030

\section{CAS Article Google Scholar}

26. Chu CL, Chen DC, Lin CC (2011) A novel adjuvant Ling Zhi-8 for cancer DNA vaccines. Hum Vaccin 7(11):1161-1164. https://doi.org/10.4161/hv.7.11.17753

CAS PubMed Article Google Scholar

27. Chung MJ, Chung CK, Jeong Y, Ham SS (2010) Anticancer activity of subfractions containing pure compounds of Chaga mushroom (Inonotus obliquus) extract in human cancer cells and in BALBC/c mice bearing sarcoma-180 cells. Nutr Res Pract 4(3):177-182. https://doi.org/10.4162/nrp.2010.4.3.177

\section{PubMed PubMed Central Article Google Scholar}

28. Clement $F$, Venkatesh YP (2010) Dietary garlic (Allium sativum) lectins, ASA I and ASA II, are highly stable and immunogenic. Int Immunopharmacol 10(10):1161-1169

CAS PubMed Article Google Scholar

29. Cutress RI, McIntosh SA, Potter S, Goyal A, Kirwan CC, Harvey J, Francis A, Carmichael AR, Vidya R, Vaidya JS, Fairbrother P, Benson JR, Reed MWR (2018) Opportunities and priorities for breast surgical research. Lancet Oncol 19(10):e521-e533. https://doi.org/10.1016/S1470-2045(18)30511-4

PubMed Article Google Scholar

30. Deng G, Lin H, Seidman A, Fornier M, D'Andrea G, Wesa K, Yeung S, CunninghamRundles S, Vickers AJ, Cassileth B (2009) A phase I/II trial of a polysaccharide extract from Grifola frondosa (Maitake mushroom) in breast cancer patients: immunological effects. J Cancer Res Clin Oncol 135(9):1215-1221. https://doi.org/10.1007/s00432-009-0562-z 
31. Deveci E, Tel-Çayan G, Duru ME, Öztürk M (2019) Isolation, characterization, and bioactivities of compounds from Fuscoporia torulosa mushroom. J Food Biochem 43(12):e13074. https://doi.org/10.1111/jfbc.13074

PubMed Article Google Scholar

32. Dong S, Furutani Y, Kimura S, Zhu Y, Kawabata K, Furutani M, Nishikawa T, Tanaka T, Masaki T, Matsuoka R, Kiyama R (2013) Brefeldin A is an estrogenic, Erk1/2-activating component in the extract of Agaricus blazei mycelia. J Agric Food Chem 61(1):128-136. https://doi.org/10.1021/jf304546a

CAS PubMed Article Google Scholar

33. Dubey SK, Chaturvedi VK, Mishra D, Bajpeyee A, Tiwari A, Singh MP (2019) Role of edible mushroom as a potent therapeutics for the diabetes and obesity. 3 Biotech 9(12):450. https://doi.org/10.1007/s13205-019-1982-3

PubMed Article Google Scholar

34. Dunneram Y, Greenwood DC, Cade JE (2019) Diet and risk of breast, endometrial and ovarian cancer: UK Women's Cohort Study. Br J Nutr 122(5):564-574

CAS PubMed Article Google Scholar

35. Eccles SA, Aboagye EO, Ali S, Anderson AS, Armes J, Berditchevski F (2013) Critical research gaps and translational prioritiesfor the successful prevention and treatment ofbreast cancer. Breast Cancer Res 15:R92. https://doi.org/10.1186/bcr3493

PubMed PubMed Central Article Google Scholar

36. El-Deeb NM, El-Adawi HI, El-Wahab AEA, Haddad AM, El Enshasy HA, He YW, Davis KR (2019) Modulation of NKG2D, KIR2DL and cytokine production by Pleurotus ostreatus glucan enhances natural killer cell cytotoxicity toward cancer cells. Front Cell Dev Biol 7:165. https://doi.org/10.3389/fcell.2019.00165

PubMed PubMed Central Article Google Scholar

37. Eliza WL, Fai CK, Chung LP (2012) Efficacy of Yun Zhi (Coriolus versicolor) on survival in cancer patients: systematic review and meta-analysis. Recent Patents Inflamm Allergy Drug Discov 6(1):78-87. https://doi.org/10.2174/187221312798889310

CAS Article Google Scholar

38. Eng C (2010) Are herbal medicines ripe for the cancer clinic? Sci Transl Med 2:1-5

Google Scholar

39. Engel CL, Rasanayagam MS, Gray JM, Rizzo J (2018) Work and breast cancer: recommendations to address research needs. New Solut 28(1):79-95. https://doi.org/10.1177/1048291118758713

PubMed Article Google Scholar

40. Erkel G, Anke T, Sterner O (1996) Inhibition of NF -kappa B kappa B kappa B kappa B activation activation by panepoxydone. Biochem Biophys Res Commun 226(1):214-21.21. https://doi.org/10.1006/bbrc.1996.1335 
41. Esquivel-Velázquez M, Ostoa-Saloma P, Palacios-Arreola MI, Nava-Castro E, Castro $\mathrm{JI}$, Morales-Montor $\mathrm{J}$ (2015) The role of cytokines in breast cancer development and pogression. J Interf Cytokine Res 35(1):1-16

\section{Article CAS Google Scholar}

42. Fan QY, Yin X, Li ZH, Li Y, Liu JK, Feng T, Zhao BH (2014) Mycophenolic acid derivatives from cultures of the mushroom Laetiporus sulphureus. Chin J Nat Med 12(9):685688. https://doi.org/10.1016/S1875-5364(14)60104-7

CAS PubMed Article Google Scholar

43. Fang N, Li Q, Yu S, Zhang J, He L, Ronis MJ, Badger TM (2006) Inhibition of growth and induction of apoptosis in human cancer cell lines by an ethyl acetate fraction from shiitake mushrooms. J Altern Complement Med 12(2):125-132. https://doi.org/10.1089/acm.2006.12.125

44. Fang X, Jiang Y, Ji H, Zhao L, Xiao W, Wang Z, Ding G (2015) The synergistic beneficial effects of Ginkgo flavonoid and Coriolus versicolor polysaccharide for memory improvements in a mouse model of dementia. Evid Based Complement Alternat Med 2015:128394. https://doi.org/10.1155/2015/128394

\section{PubMed PubMed Central Article Google Scholar}

45. Fangkrathok N, Sripanidkulchai B, Umehara K, Noguchi H (2013) Bioactive ergostanoids and a new polyhydroxyoctane from Lentinus polychrous mycelia and their inhibitory effects on E2-enhanced cell proliferation of T47D cells. Nat Prod Res 27(18):16111619. https://doi.org/10.1080/14786419.2012.742079

\section{CAS PubMed Article Google Scholar}

46. Feng W, Yang J, Xu X, Liu Q (2010) Quantitative determination of lanostane triterpenes in Fomes officinalis and their fragmentation study by HPLC-ESI. Phytochem Anal 21(6):531538. https://doi.org/10.1002/pca.1228

\section{CAS PubMed Article Google Scholar}

47. Ferrigni E, Bergom C, Yin Z, Szabo A, Kong AL (2019) Breast cancer in women aged 80 years or older: an analysis of treatment patterns and disease outcomes. Clin Breast Cancer 19(3):157-164

\section{PubMed Article Google Scholar}

48. Frenkel M, Abrams DI, Ladas EJ, Deng G, Hardy M, Capodice JL, Winegardner MF, Gubili JK, Yeung KS, Kussmann H, Block KI (2013) Integrating dietary supplements into cancer care. Integr Cancer Ther 12(5):369-384. https://doi.org/10.1177/1534735412473642

49. Fujii T, Saito K, Oguchi Y, Matsunaga K, Kobayashi Y, Yoshikumi C, Taguchi T (1988) Effects of the protein-bound polysaccharide preparation, PSK on spontaneous breast cancer in mice. J Int Med Res 16(4):286-293. https://doi.org/10.1177/030006058801600406

\section{CAS PubMed Article Google Scholar}

50. Fung SY, Tan NH, Kong BH, Lee SS, Tan YS, Sabaratnam V (2017) Acute toxicity study and the in vitro cytotoxicity of a black Lingzhi medicinal mushroom, Amauroderma rugosum (Agaricomycetes), from Malaysia. Int J Med Mushrooms 19(12):1093-1099. https://doi.org/10.1615/IntJMedMushrooms.2017024550 


\section{PubMed Article Google Scholar}

51. Gabor F, Wirth M, Jurkovich B, Haberl I, Theyer G, Walcher G, Hamilton G (1997) Lectin-mediated bioadhesion: proteolytic stability and binding-characteristics of wheat germ agglutinin and Solanum tuberosum lectin on Caco-2, HT-29 and human colonocytes. J Control Release 49(1):27-37

\section{CAS Article Google Scholar}

52. Ghasemi F, Sarabi PZ, Athari SS, Esmaeilzadeh A (2019) Therapeutics strategies against cancer stem cell in breast cancer. Int J Biochem Cell Biol 109:76-81. https://doi.org/10.1016/j.biocel.2019.01.015

\section{CAS PubMed Article Google Scholar}

53. Gong S, Zhang HQ, Yin WP, Yin QZ, Zhang Y, Gu ZL, Qian ZM, Tang PL (1998) Involvement of interleukin-2 in analgesia produced by Coriolus versicolor polysaccharide peptides. Zhongguo Yao Li Xue Bao 19(1):67-70

\section{CAS PubMed Google Scholar}

54. Gonul O, Aydin HH, Kalmis E, Kayalar H, Ozkaya AB, Atay S, Ak H (2015) Effects of Ganoderma lucidum (higher Basidiomycetes) extracts on the miRNA profile and telomerase activity of the MCF-7 breast cancer cell line. Int J Med Mushrooms 17(3):231-239. https://doi.org/10.1615/intjmedmushrooms.v17.i3.30

\section{PubMed Article Google Scholar}

55. Gu YH, Leonard J (2006) In vitro effects on proliferation, apoptosis and colony inhibition in ER-dependent and ER-independent human breast cancer cells by selected mushroom species. Oncol Rep 15(2):417-423. https://doi.org/10.1615/intjmedmushrooms.v17.i3.30

PubMed Article Google Scholar

56. Hao J, Zhang X, Yu W, Wang R, Xue Z, Kou X (2017) Identification and evaluation of bioactivity of compounds from the mushroom Pleurotus nebrodensis (Agaricomycetes) against breast cancer. Int J Med Mushrooms 19(9):839-848. https://doi.org/10.1615/IntJMedMushrooms.2017024372

\section{PubMed Article Google Scholar}

57. Haque MA, Islam MAU (2019) Pleurotus highking mushroom induces apoptosis by altering the balance of proapoptotic and antiapoptotic genes in breast cancer cells and inhibits tumor sphere formation. Medicina (Kaunas) 55(11):E716. https://doi.org/10.3390/medicina55110716

\section{Article Google Scholar}

58. He JB, Tao J, Miao XS, Bu W, Zhang S, Dong ZJ, Li ZH, Feng T, Liu JK (2015) Seven new drimane-type sesquiterpenoids from cultures of fungus Laetiporus sulphureus. Fitoterapia. 102:1-6. https://doi.org/10.1016/j.fitote.2015.01.022

CAS PubMed Article Google Scholar

59. Ho CY, Lau CB, Kim CF, Leung KN, Fung KP, Tse TF, Chan HH, Chow MS (2004a) Differential effect of Coriolus versicolor (Yunzhi) extract on cytokine production by murine lymphocytes in vitro. Int Immunopharmacol 4(12):1549-1557. https://doi.org/10.1016/j.intimp.2004.07.021 
60. Ho JC, Konerding MA, Gaumann A, Groth M, Liu WK (2004b) Fungal polysaccharopeptide inhibits tumor angiogenesis and tumor growth in mice. Life Sci 75(11):1343-1356. https://doi.org/10.1016/j.lfs.2004.02.021

CAS PubMed Article Google Scholar

61. Ho CY, Kim CF, Leung KN, Fung KP, Tse TF, Chan H, Lau CB (2005) Differential antitumor activity of Coriolus versicolor (Yunzhi) extract through p53- and/or Bcl-2-dependent apoptotic pathway in human breast cancer cells. Cancer Biol Ther 4(6):638-644. https://doi.org/10.4161/cbt.4.6.1721

\section{PubMed Article Google Scholar}

62. Ho CY, Kim CF, Leung KN, Fung KP, Tse TF, Chan H, Lau CB (2006) Coriolus versicolor (Yunzhi) extract attenuates growth of human leukemia xenografts and induces apoptosis through the mitochondrial pathway. Oncol Rep 16(3):609-616

CAS PubMed Google Scholar

63. Hong SA, Kim K, Nam SJ, Kong G, Kim MK (2008) A case-control study on the dietary intake of mushrooms and breast cancer risk among Korean women. Int J Cancer 122(4):919923

CAS PubMed Article Google Scholar

64. Houghton LC, Howland RE, McDonald JA (2019) Mobilizing breast cancer prevention research through smartphone apps: a systematic review of the literature. Front Public Health 7:298. https://doi.org/10.3389/fpubh.2019.00298

PubMed PubMed Central Article Google Scholar

65. Hseu YC, Chang GR, Pan JY, Rajendran P, Mathew DC, Li ML, Liao JW, Chen WT, Yang HL (2019a) Antrodia camphorata inhibits epithelial-to-mesenchymal transition by targeting multiple pathways in triple-negative breast cancers. J Cell Physiol 234(4):4125-4139. https://doi.org/10.1002/jcp.27222

\section{CAS PubMed Article Google Scholar}

66. Hseu YC, Lin YC, Rajendran P, Thigarajan V, Mathew DC, Lin KY, Way TD, Liao JW, Yang HL (2019b) Antrodia salmonea suppresses invasion and metastasis in triple negative breast cancer cells by reversing EMT through the NF-KB and Wnt/ $\beta$-catenin signaling pathway. Food Chem Toxicol 124:219-230. https://doi.org/10.1016/j.fct.2018.12.009

67. Hsu KD, Cheng KC (2018) From nutraceutical to clinical trial: frontiers in Ganoderma development. Appl Microbiol Biotechnol 102(21):9037-9051. https://doi.org/10.1007/s00253018-9326-5

CAS PubMed Article Google Scholar

68. Hu H, Ahn NS, Yang X, Lee YS, Kang KS (2002) Ganoderma lucidum extract induces cell cycle arrest and apoptosis in MCF-7 human breast cancer cell. Int J Cancer 102(3):250253. https://doi.org/10.1002/ijc.10707

CAS PubMed Article Google Scholar 
69. Hu Y, Zhu M, Tian G, Zhao L, Wang H, Ng TB (2017) Isolation of a protease-resistant and $\mathrm{pH}$-stable $\alpha$-galactosidase displaying hydrolytic efficacy toward raffinose family oligosaccharides from the button mushroom Agaricus bisporus. Int J Biol Macromol 104:576583

\section{CAS PubMed Article Google Scholar}

70. Hu B, Yan W, Wang M, Cui X, Hu Y, Chen Q, Zhang Y, Qi X, Jiang J (2019) Huaier polysaccharide inhibits the stem-like characteristics of ERa-36(high) triple negative breast cancer cells via inactivation of the ERa-36 signaling pathway. Int J Biol Sci 15(7):1358-1367. https://doi.org/10.7150/ijbs.27360

CAS PubMed PubMed Central Article Google Scholar

71. Huang WT, Tai R, Hseu RS, Huang CT (2011) Overexpression and characterization of a thermostable, $\mathrm{pH}$-stable and organic solvent-tolerant Ganoderma fornicatum laccase in Pichia pastoris. Process Biochem 46:1469-1474

\section{CAS Article Google Scholar}

72. lino $\mathrm{Y}$, Yokoe T, Maemura M, Horiguchi J, Takei H, Ohwada S, Morishita Y (1995) Immunochemotherapies versus chemotherapy as adjuvant treatment after curative resection of operable breast cancer. Anticancer Res 15(6B):2907-2911

\section{CAS PubMed Google Scholar}

73. Israilides C, Kletsas D, Arapoglou D, Philippoussis A, Pratsinis H, Ebringerová A, Hríbalová V, Harding SE (2008) In vitro cytostatic and immunomodulatory properties of the medicinal mushroom Lentinula edodes. Phytomedicine. 15(6-7):512-519. https://doi.org/10.1016/j.phymed.2007.11.029

\section{CAS PubMed Article Google Scholar}

74. Jang EH, Jang SY, Cho IH, Hong D, Jung B, Park MJ, Kim JH (2015) Hispolon inhibits the growth of estrogen receptor positive human breast cancer cells through modulation of estrogen receptor alpha. Biochem Biophys Res Commun 463(4):917-922. https://doi.org/10.1016/j.bbrc.2015.06.035

\section{CAS PubMed Article Google Scholar}

75. Jedinak A, Sliva D (2008) Pleurotus ostreatus inhibits proliferation of human breast and colon cancer cells through p53-dependent as well as p53-independent pathway. Int J Oncol 33(6):1307-1313

\section{PubMed PubMed Central Google Scholar}

76. Jeong MH, Lee CM, Lee SW, Seo SY, Seo MJ, Kang BW, Jeong YK, Choi YJ, Yang KM, Jo WS (2013) Cordycepin-enriched Cordyceps militaris induces immunomodulation and tumor growth delay in mouse-derived breast cancer. Oncol Rep 30(4):1996-2002. https://doi.org/10.3892/or.2013.2660

\section{CAS PubMed Article Google Scholar}

77. Jia W, Feng J, Zhang JS, Lin CC, Wang WH, Chen HG (2017) Structural characteristics of the novel polysaccharide FVPA1 from winter culinary-medicinal mushroom, Flammulina velutipes (Agaricomycetes), capable of enhancing natural killer cell activity against K562 tumor 
$\begin{array}{lllll}\text { cells. Int } & \mathrm{J} & \text { Med } & \text { Mushrooms }\end{array}$ https://doi.org/10.1615/IntJMedMushrooms.v19.i6.50

78. Jiang J, Sliva D (2010) Novel medicinal mushroom blend suppresses growth and invasiveness of human breast cancer cells. Int $J$ Oncol 37(6):1529-1536. https://doi.org/10.3892/ijo_00000806

PubMed Article Google Scholar

79. Jiang J, Slivova V, Sliva D (2006) Ganoderma lucidum inhibits proliferation of human breast cancer cells by down-regulation of estrogen receptor and NF-kappaB signaling. Int $\mathrm{J}$ Oncol 29(3):695-703

\section{CAS PubMed Google Scholar}

80. Jiang J, Jedinak A, Sliva D (2011) Ganodermanontriol (GDNT) exerts its effect on growth and invasiveness of breast cancer cells through the down-regulation of CDC20 and uPA. Biochem Biophys Res Commun 415(2):325-329. https://doi.org/10.1016/j.bbrc.2011.10.055

CAS PubMed Article Google Scholar

81. Jiang J, Thyagarajan-Sahu A, Loganathan J, Eliaz I, Terry C, Sandusky GE, Sliva D (2012) BreastDefend ${ }^{\mathrm{TM}}$ prevents breast-to-lung cancer metastases in an orthotopic animal model of triple-negative human breast cancer. Oncol Rep 28(4):1139-1145. https://doi.org/10.3892/or.2012.1936

PubMed PubMed Central Article Google Scholar

82. Jiao C, Xie YZ, Yang X, Li H, Li XM, Pan HH, Cai MH, Zhong HM, Yang BB (2013) Anticancer activity of Amauroderma rude. PLoS One 8(6):e66504. https://doi.org/10.1371/journal.pone.0066504

CAS PubMed PubMed Central Article Google Scholar

83. Jiao C, Chen W, Tan X, Liang H, Li J, Yun H, He C, Chen J, Ma X, Xie Y, Yang BB (2020) Ganoderma lucidum spore oil induces apoptosis of breast cancer cells in vitro and in vivo by activating caspase-3 and caspase-9. J Ethnopharmacol 247:112256. https://doi.org/10.1016/j.jep.2019.112256

CAS PubMed Article Google Scholar

84. Jiménez-Medina E, Berruguilla E, Romero I, Algarra I, Collado A, Garrido F, GarciaLora A (2008) The immunomodulator PSK induces in vitro cytotoxic activity in tumour cell lines via arrest of cell cycle and induction of apoptosis. BMC Cancer 8:78. https://doi.org/10.1186/1471-2407-8-78

\section{CAS PubMed PubMed Central Article Google Scholar}

85. Jin CY, Kim GY, Choi YH (2008) Induction of apoptosis by aqueous extract of Cordyceps militaris through activation of caspases and inactivation of Akt inhuman breast cancer MDA-MB-231 Cells. J Microbiol Biotechnol 18(12):1997-2003

CAS PubMed Google Scholar

86. Jin Y, Meng X, Qiu Z, Su Y, Yu P, Qu P (2018) Anti-tumor and anti-metastatic roles of cordycepin, one bioactive compound of Cordyceps militaris. Saudi J Biol Sci 25(5):991-995. https://doi.org/10.1016/j.sjbs.2018.05.016 
87. Jordan JL, Nowak A, Lee TD (2010) Activation of innate immunity to reduce lung metastases in breast cancer. Cancer Immunol Immunother 59(5):789-797. https://doi.org/10.1007/s00262-009-0800-x

PubMed Article Google Scholar

88. Jung JW, Moon SM, Park BR, Kim SG, Kim JS, Kim CS (2014) Anti-cancer activity of the protein extract from Lyophyllum shimeji in KB human oral squamous cell carcinoma. Oral Biol Res 38(2):99-105

89. Khan MA, Tania M (2018) Cordycepin in anticancer research: molecular mechanism of therapeutic effects. Curr Med Chem. https://doi.org/10.2174/0929867325666181001105749

90. Kidd PM (2000) The use of mushroom glucans and proteoglycans in cancer treatment. Altern Med Rev 5(1):4-27

CAS PubMed Google Scholar

91. Kim TH, Kim JS, Kim ZH, Huang RB, Chae YL, Wang RS (2016) Induction of apoptosis in MCF-7 human breast cancer cells by Khz (fusion of Ganoderma lucidum and Polyporus umbellatus mycelium). Mol Med Rep 13(2):1243-1249. https://doi.org/10.3892/mmr.2015.4655

CAS PubMed Article Google Scholar

92. Ko CH, Yue GG, Gao S, Luo KW, Siu WS, Shum WT, Shiu HT, Lee JK, Li G, Leung PC, Evdokiou A, Lau CB (2017) Evaluation of the combined use of metronomic zoledronic acid and Coriolus versicolor in intratibial breast cancer mouse model. J Ethnopharmacol 204:7785. https://doi.org/10.1016/j.jep.2017.04.007

\section{CAS PubMed Article Google Scholar}

93. Kodama N, Komuta K, Nanba H (2003) Effect of Maitake (Grifola frondosa) D-Fraction on the activation of NK cells in cancer patients. J Med Food 6(4):371-377. https://doi.org/10.1089/109662003772519949

\section{CAS PubMed Article Google Scholar}

94. Konagai A, Yoshimura K, Hazama S, Yamamoto N, Aoki K, Ueno T, Fujioka M, lijima $H$, Kato M, Ichida M, Wada T, Inoue M, Asao T, Fuse M, Wada S, Kuramasu A, Kamei R, Takeda S, Yamamoto S, Yoshino S, Oka M, Nagano H (2017) Correlation between NKG2DL expression and antitumor effect of protein-bound polysaccharide-K in tumor-bearing mouse models. Anticancer Res 37(8):4093-4101. https://doi.org/10.21873/anticanres.11796

CAS PubMed Article Google Scholar

95. Konno S, Chu K, Feuer N, Phillips J, Choudhury M (2015) Potent anticancer effects of bioactive mushroom extracts (Phellinus linteus) on a variety of human cancer cells. J Clin Med Res 7(2):76-82. https://doi.org/10.14740/jocmr1996w

CAS PubMed Article Google Scholar

96. Kosaka A, Wani T, Hattori Y, Yamashita A (1982) Effect of lentinan administration of adrenalectomized rats and patients with breast cancer. Gan To Kagaku Ryoho 9(8):14741481

CAS PubMed Google Scholar 
97. Kowalczewska M, Piotrowski J, Jędrzejewski T, Kozak W (2016) Polysaccharide peptides from Coriolus versicolor exert differential immunomodulatory effects on blood lymphocytes and breast cancer cell line MCF-7 in vitro. Immunol Lett 174:37-44. https://doi.org/10.1016/j.imlet.2016.04.010

\section{CAS PubMed Article Google Scholar}

98. Krasnopolskaya LM, Shuktueva MI, Avtonomova AV, Yarina MS, Dzhavakhyan BR, Isakova EB, Bukhman VM (2016) Antitumor and antioxidant properties of water-soluble polysaccharides from submerged mycelium of Flammulina velutipes. Antibiot Khimioter 61(1112):16-20

\section{CAS PubMed Google Scholar}

99. Krishnamoorthy D, Sankaran M (2016) Modulatory effect of Pleurotus ostreatus on oxidant/antioxidant status in 7, 12-dimethylbenz (a) anthracene induced mammary carcinoma in experimental rats-a dose-response study. J Cancer Res Ther 12(1):386-394. https://doi.org/10.4103/0973-1482.148691

CAS PubMed Article Google Scholar

100. Kumar KJS, Vani MG, Hsieh HW, Lin CC, Wang SY (2019) Antcin-A modulates epithelial-to-mesenchymal transition and inhibits migratory and invasive potentials of human breast cancer cells via p53-mediated miR-200c activation. Planta Med 85(9-10):755-765. https://doi.org/10.1055/a-0942-2087

CAS PubMed Article Google Scholar

101. Lau CB, Ho CY, Kim CF, Leung KN, Fung KP, Tse TF, Chan HH, Chow MS (2004) Cytotoxic activities of Coriolus versicolor (Yunzhi) extract on human leukemia and lymphoma cells by induction of apoptosis. Life Sci 75(7):797-808

102. Lavi I, Friesem D, Geresh S, Hadar Y, Schwartz B (2006) An aqueous polysaccharide extract from the edible mushroom Pleurotus ostreatus induces anti-proliferative and proapoptotic effects on HT-29 colon cancer cells. Cancer Lett 244(1):61-70

CAS PubMed Article Google Scholar

103. Lavi I, Levinson D, Peri I, Tekoah Y, Hadar Y, Schwartz B (2010) Chemical characterization, antiproliferative and antiadhesive properties of polysaccharides extracted from Pleurotus pulmonarius mycelium and fruiting bodies. Appl Microbiol Biotechnol 85(6):1977-1990. https://doi.org/10.1007/s00253-009-2296-x

CAS PubMed Article Google Scholar

104. Lavi I, Nimri L, Levinson D, Peri I, Hadar Y, Schwartz B (2012) Glucans from the edible mushroom Pleurotus pulmonarius inhibit colitis-associated colon carcinogenesis in mice. $J$ Gastroenterol 47(5):504-518. https://doi.org/10.1007/s00535-011-0514-7

CAS PubMed Article Google Scholar

105. Lee CC, Yang HL,Way TD, Kumar KJ, Juan YC, Cho HJ, Lin KY, Hsu LS, Chen SC, Hseu YC (2012) Inhibition of cell growth and induction of apoptosis by Antrodia camphorata in HER-2/neu-overexpressing breast cancer cells through the induction of ROS, depletion of HER-2/neu, and disruption of the PI3K/Akt signaling pathway. Evid Based Complement Alternat Med 2012:702857. https://doi.org/10.1155/2012/702857 
106. Lee D, Lee WY, Jung K, Kwon YS, Kim D, Hwang GS, Kim CE, Lee S, Kang KS (2019a) The inhibitory effect of cordycepin on the proliferation of MCF-7 breast cancer cells, and its mechanism: an investigation using network pharmacology-based analysis. Biomolecules 9(9):E407. https://doi.org/10.3390/biom9090407

\section{CAS PubMed Article Google Scholar}

107. Lee SO, Lee MH, Lee KR, Lee EO, Lee HJ (2019b) Fomes fomentarius ethanol extract exerts inhibition of cell growth and motility induction of apoptosis via targeting AKT in human breast cancer MDA-MB-231 cells. Int J Mol Sci 20(5):E1147. https://doi.org/10.3390/ijms20051147

CAS PubMed Article Google Scholar

108. Lee SR, Seok S, Ryoo R, Choi SU, Kim KH (2019c) Macrocyclic trichothecene mycotoxins from a deadly poisonous mushroom, Podostroma cornu-damae. J Nat Prod 82(1):122-128. https://doi.org/10.1021/acs.jnatprod.8b00823

CAS PubMed Article Google Scholar

109. Li M, Zhang G, Wang H, Ng T (2010a) Purification and characterization of a laccase from the edible wild mushroom Tricholoma mongolicum. J Microbiol Biotechnol 20(7):10691076. https://doi.org/10.4014/jmb.0912.12033

CAS PubMed Article Google Scholar

110. Li Y, Zhang G, Ng TB, Wang H (2010b) A novel lectin with antiproliferative and HIV-1 reverse transcriptase inhibitory activities from dried fruiting bodies of the monkey head mushroom Hericium erinaceum. J Biomed Biotechnol 2010:716515. https://doi.org/10.1155/2010/716515

\section{CAS PubMed PubMed Central Article Google Scholar}

111. Li F, Wang Y, Wang X, Li J, Cui H, Niu M (2012) Ganoderic acids suppress growth and angiogenesis by modulating the NF-kB signaling pathway in breast cancer cells. Int $\mathrm{J}$ Clin Pharmacol Ther 50(10):712-721. https://doi.org/10.5414/CP201663

CAS PubMed Article Google Scholar

112. Li M, Wang H, Ng TB (2013) Isolation of a phytase with distinctive characteristics from an edible mushroom, Pleurotus eryngii. Protein Pept Lett 20(4):459-466

CAS PubMed Google Scholar

113. Li X, Wu Q, Xie Y, Ding Y, Du WW, Sdiri M, Yang BB (2015) Ergosterol purified from medicinal mushroom Amauroderma rude inhibits cancer growth in vitro and in vivo by upregulating multiple tumor suppressors. Oncotarget 6(19):17832-17846. https://doi.org/10.18632/oncotarget.4026

PubMed PubMed Central Article Google Scholar

114. Li X, He Y, Zeng P, Liu Y, Zhang M, Hao C, Wang H, Lv Z, Zhang L (2019) Molecular basis for Poria cocos mushroom polysaccharide used as an antitumour drug in China. $\mathrm{J}$ Cell Mol Med 23(1):4-20. https://doi.org/10.1111/jcmm.13564

CAS PubMed Article Google Scholar 
115. Lin YS, Lin YY, Yang YH, Lin CL, Kuan FC, Lu CN, Chang GH, Tsai MS, Hsu CM, Yeh RA, Yang PR, Lee IY, Shu LH, Cheng YC, Liu HT, Lee KD, Chang DC, Wu CY (2018) Antrodia cinnamomea extract inhibits the proliferation of tamoxifen-resistant breast cancer cells through apoptosis and skp2/microRNAs pathway. BMC Complement Altern Med 18(1):152. https://doi.org/10.1186/s12906-018-2204-y

CAS PubMed PubMed Central Article Google Scholar

116. Linh DT, Hien BT, do Que D, Lam DM, Arnold N, Schmidt J, Porzel A, Quang DN (2014) Cytotoxic constituents from the Vietnamese fungus Xylaria schweinitzii. Nat Prod Commun 9(5):659-660

\section{CAS PubMed Google Scholar}

117. Liu WK, Ng TB, Sze SF, Tsui KW (1993) Activation of peritoneal macrophages by polysaccharopeptide from the mushroom. Coriolus Versicolor Immunopharmacol 26(2):139146. https://doi.org/10.1016/0162-3109(93)90006-c

\section{CAS Article Google Scholar}

118. Liu YW, Gao JL, Guan J, Qian ZM, Feng K, Li SP (2009) Evaluation of antiproliferative activities and action mechanisms of extracts from two species of Ganoderma on tumor cell lines. J Agric Food Chem 57(8):3087-3093. https://doi.org/10.1021/jf900011f

\section{CAS PubMed Article Google Scholar}

119. Loganathan J, Jiang J, Smith A, Jedinak A, Thyagarajan-Sahu A, Sandusky GE, Nakshatri H, Sliva D (2014) The mushroom Ganoderma lucidum suppresses breast-to-lung cancer metastasis through the inhibition of pro-invasive genes. Int J Oncol 44(6):2009-2015. https://doi.org/10.3892/ijo.2014.2375

\section{PubMed PubMed Central Article Google Scholar}

120. Lu H, Yang Y, Gad E, Inatsuka C, Wenner CA, Disis ML, Standish LJ (2011) TLR2 agonist PSK activates human NK cells and enhances the antitumor effect of HER2-targeted monoclonal antibody therapy. Clin Cancer Res 17(21):6742-6753. https://doi.org/10.1158/1078-0432.CCR-11-1142

\section{CAS PubMed PubMed Central Article Google Scholar}

121. Luo KW, Yue GG, Ko CH, Lee JK, Gao S, Li LF, Li G, Fung KP, Leung PC, Lau CB (2014) In vivo and in vitro anti-tumor and anti-metastasis effects of Coriolus versicolor aqueous extract on mouse mammary 4T1 carcinoma. Phytomedicine. 21(8-9):1078-1087. https://doi.org/10.1016/j.phymed.2014.04.020

PubMed Article Google Scholar

122. Ma L, Chen H, Dong P, Lu X (2013 Aug 15) Anti-inflammatory and anticancer activities of extracts and compounds from the mushroom Inonotus obliquus. Food Chem 139(1-4):503508. https://doi.org/10.1016/j.foodchem.2013.01.030

\section{CAS PubMed Article Google Scholar}

123. Mansour A, Daba A, Baddour N, El-Saadani M, Aleem E (2012) Schizophyllan inhibits the development of mammary and hepatic carcinomas induced by 7,12 dimethylbenz $(\alpha)$ anthracene and decreases cell proliferation: comparison with tamoxifen. $J$ Cancer Res Clin Oncol 138(9):1579-1596. https://doi.org/10.1007/s00432-012-1224-0 


\section{CAS PubMed Article Google Scholar}

124. Martínez-Montemayor MM, Ling T, Suárez-Arroyo IJ, Ortiz-Soto G, Santiago-Negrón CL, Lacourt-Ventura MY, Valentín-Acevedo A, Lang WH, Rivas F (2019) Identification of biologically active Ganoderma lucidum compounds and synthesis of improved derivatives that confer anti-cancer activities in vitro. Front Pharmacol 10:15. https://doi.org/10.3389/fphar.2019.00115

\section{CAS Article Google Scholar}

125. Mizerska-Dudka M, Jaszek M, Błachowicz A, Rejczak TP, Matuszewska A, OsińskaJaroszuk M, Stefaniuk D, Janusz G, Sulej J, Kandefer-Szerszeń M (2015) Fungus Cerrena unicolor as an effective source of new antiviral, immunomodulatory, and anticancer compounds. Int J Biol Macromol 79:459-468. https://doi.org/10.1016/j.ijbiomac.2015.05.015

CAS PubMed Article Google Scholar

126. Monro JA (2003) Treatment of cancer with mushroom products. Arch Environ Health 58(8):533-537. https://doi.org/10.3200/AEOH.58.8.533-537

\section{PubMed Article Google Scholar}

127. Morino M, Tsuzuki T, Ishikawa $Y$, Shirakami T, Yoshimura M, Kiyosuke Y, Matsunaga K, Yoshikumi C, Saijo N (1997) Specific regulation of HSPs in human tumor cell lines by PSK. In Vivo 11(3):261-264

\section{CAS PubMed Google Scholar}

128. Nagajyothi PC, Sreekanth TV, Lee Jl, Lee KD (2014) Mycosynthesis: antibacterial, antioxidant and antiproliferative activities of silver nanoparticles synthesized from Inonotus obliquus (Chaga mushroom) extract. J Photochem Photobiol B 130:299-304. https://doi.org/10.1016/j.jphotobiol.2013.11.022

129. Nagashima Y, Sanpei N, Yamamoto S, Yoshino S, Tangoku A, Oka M (2005) Evaluation of host immunity and side effects in breast cancer patients treated with adjuvant chemotherapy (FEC therapy). Gan To Kagaku Ryoho 32(11):1550-1552

\section{CAS PubMed Google Scholar}

130. Nakamura K, Shinozuka K, Yoshikawa N (2015) Anticancer and antimetastatic effects of cordycepin, an active component of Cordyceps sinensis. J Pharmacol Sci 127(1):53-56. https://doi.org/10.1016/j.jphs.2014.09.001

131. $\mathrm{Ng}$ TB (1998) A review of research on the protein-bound polysaccharide (polysaccharopeptide, PSP) from the mushroom Coriolus versicolor (Basidiomycetes: Polyporaceae). Gen Pharmacol 30(1):1-4. https://doi.org/10.1016/s0306-3623(97)00076-1

\section{CAS PubMed Article Google Scholar}

132. Ng TB, Chan WY (1997) Polysaccharopeptide from the mushroom Coriolus versicolor possesses analgesic activity but does not produce adverse effects on female reproductive or embryonic development in mice. Gen Pharmacol 29(2):269-273. https://doi.org/10.1016/s0306-3623(96)00412-0

133. Nimri L, Spivak O, Tal D, Schälling D, Peri I, Graeve L, Salame TM, Yarden O, Hadar $Y$, Schwartz B et al (2017) Oncotarget 8(17):28854-28864. https://doi.org/10.18632/oncotarget.15859 


\section{PubMed PubMed Central Article Google Scholar}

134. Novaković A, Karaman M, Kaišarević, S, Novi S, Radusin, T, (2019) Auricularia auricula-judae (Bull.: fr.) Wettst. 1885 cytotoxicity on breast cancer cell line (MCF 7), Proceedings of III International Congress Food Technology, Quality and Safety. In AGRIS, 113-116. Publisher Institute of Food Technology, Novi Sad (Serbia). ISBN 978-86-7994-0506.

135. Palacios S, Losa F, Dexeus D, Cortés J (2017) Beneficial effects of a Coriolus versicolor-based vaginal gel on cervical epithelization, vaginal microbiota and vaginal health: a pilot study in asymptomatic women. BMC Womens Health 17(1):21. https://doi.org/10.1186/s12905-017-0374-2

CAS PubMed PubMed Central Article Google Scholar

136. Pan WL, Wong JH, Fang EF, Chan YS, Ye XJ, Ng TB (2013) Differential inhibitory potencies and mechanisms of the type I ribosome inactivating protein marmorin on estrogen receptor (ER)-positive and ER-negative breast cancer cells. Biochim Biophys Acta 1833(5):987-996. https://doi.org/10.1016/j.bbamcr.2012.12.013

137. Park JH, Ryu CS, Kim HN, Na YJ, Park HJ, Kim H (2004) A sialic acid-specific lectin from the mushroom Paecilomyces japonica that exhibits hemagglutination activity and cytotoxicity. Protein Pept Lett 11(6):563-569. https://doi.org/10.2174/0929866043406445

CAS PubMed Article Google Scholar

138. Partridge AH, Carey LA (2017) Unmet needs in clinical research in breast cancer: where do we need to go? Clin Cancer Res 23(11):2611-2616. https://doi.org/10.1158/10780432.CCR-16-2633

139. Patel S, Goyal A (2012) Recent developments in mushrooms as anti-cancer therapeutics: a review. 3 Biotech 2(1):1-15

PubMed Article Google Scholar

140. Pawlikowska M, Jędrzejewski T, Piotrowski J, Kozak W (2016) Fever-range hyperthermia inhibits cells immune response to protein-bound polysaccharides derived from Coriolus versicolor extract. Mol Immunol 80:50-57. https://doi.org/10.1016/j.molimm.2016.10.013

141. Petrova RD, Mahajna J, Wasser SP, Ruimi N, Denchev CM, Sussan S, Nevo E, Reznick AZ (2009) Marasmius oreades substances block NF-kappaB activity through interference with IKK activation pathway. Mol Biol Rep 36(4):737-744. https://doi.org/10.1007/s11033-008-9237-0

CAS PubMed Article Google Scholar

142. Qi ZH, Meng J, Wang ZL, Sun HZ, Gong Y (2016) Antitumor effect of Ganoderma lipsiense extract on triple-negative breast cancer model mice and mechanism study. Zhongguo Zhong Xi Yi Jie He Za Zhi 36(3):366-369

PubMed Google Scholar

143. Qian L, Zhang Y, Liu F (2016) Purification and characterization of a $\sim 43 \mathrm{kDa}$ antioxidant protein with antitumor activity from Pholiota nameko. J Sci Food Agric 96(3):1044-1052. https://doi.org/10.1002/jsfa.7194 
144. Qin P, Li X, Yang H, Wang ZY, Lu D (2019) Therapeutic potential and biological applications of cordycepin and metabolic mechanisms in cordycepin-producing fungi. Molecules 24(12):E2231. https://doi.org/10.3390/molecules24122231

\section{CAS PubMed Article Google Scholar}

145. Qiu J, Zhang H, Wang Z (2018a) Auricularia auriculajudae polysaccharide-cisplatin complexes conjugated with folic acid as new tumor targeting agents. Int J Biol Macromol $120(\mathrm{Pt}$ A):966-974. https://doi.org/10.1016/j.jibiomac.2018.05.051

\section{CAS PubMed Article Google Scholar}

146. Qiu J, Zhang H, Wang Z, Liu D, Liu S, Han W, Regenstein JM, Geng L (2018b) The antitumor effect of folic acid conjugated-Auricularia auricular polysaccharide-cisplatin complex on cervical carcinoma cells in nude mice. Int $\mathrm{J}$ Biol Macromol 107(Pt B):2180-2189. https://doi.org/10.1016/j.ijbiomac.2017.10.087

\section{CAS PubMed Article Google Scholar}

147. Rachmawati $\mathrm{H}$, Sundari S, Nabila N, Tandrasasmita OM, Amalia R, Siahaan TJ, Tjandrawinata RR, Ismaya WT (2019) Orf239342 from the mushroom Agaricus bisporus is a mannose binding protein. Biochem Biophys Res Commun 515(1):99-103. https://doi.org/10.1016/j.bbrc.2019.05.107

\section{CAS PubMed Article Google Scholar}

148. Ramesh V, Santosh K, Anand TD, Shanmugaiah V, Kotamraju S, Karunakaran C, Rajendran A (2015) Novel bioactive wild medicinal mushroom-Xylaria sp. R006 (Ascomycetes) against multidrug resistant human bacterial pathogens and human cancer cell lines. Int J Med Mushrooms 17(10):1005-1017. https://doi.org/10.1615/intjmedmushrooms.v17.i10.100

149. Rao YK, Wu AT, Geethangili M, Huang MT, Chao WJ, Wu CH, Deng WP, Yeh CT, Tzeng YM (2011) Identification of antrocin from Antrodia camphorata as a selective and novel class of small molecule inhibitor of Akt/mTOR signaling in metastatic breast cancer MDA-MB231 cells. Chem Res Toxicol 24(2):238-245. https://doi.org/10.1021/tx100318m

150. Rios-Fuller TJ, Ortiz-Soto G, Lacourt-Ventura M, Maldonado-Martinez G, Cubano LA, Schneider RJ, Martinez-Montemayor MM (2018) Ganoderma lucidum extract (GLE) impairs breast cancer stem cells by targeting the STAT3 pathway. Oncotarget 9(89):35907-35921. https://doi.org/10.18632/oncotarget.26294

\section{PubMed PubMed Central Article Google Scholar}

151. Rodríguez-Valentín M, López S, Rivera M, Ríos-Olivares E, Cubano L, Boukli NM (2018) Naturally derived anti-HIV polysaccharide peptide (PSP) triggers a Toll-like receptor 4dependent antiviral immune response. J Immunol Res 2018:8741698. https://doi.org/10.1155/2018/87416989

\section{PubMed PubMed Central Article Google Scholar}

152. Roldan-Deamicis A, Alonso E, Brie B, Braico DA, Balogh GA (2016) Maitake Pro4X has anti-cancer activity and prevents oncogenesis in BALBc mice. Cancer Med 5(9):24272441. https://doi.org/10.1002/cam4.744

CAS PubMed PubMed Central Article Google Scholar 
153. Rossiana N, Madihah, Nur AA, Mayawatie B, Andayaningsih P (2018) Cytotoxicity assay of ethyl acetate extract shimeji (Lyophyllum shimeji (Kawam.) Hongo) and white oyster mushroom (Pleurotus ostreatus Jacq.) against HCT-116 cell line. IOP Conf Ser: Earth and Environmental Science 197:012007. https://doi.org/10.1088/1755-1315/197/1/012007

\section{Article Google Scholar}

154. Saleh $\mathrm{MH}$, Rashedi I, Keating A (2017) Immunomodulatory properties of Coriolus versicolor: the role of polysaccharopeptide. Front Immunol 8:1087. https://doi.org/10.3389/fimmu.2017.01087

\section{CAS PubMed PubMed Central Article Google Scholar}

155. Santibanez JF, Terzic M, Vesovic D, Bugarski D (2013) GE132+Natural: novel promising dietetic supplement with antiproliferative influence on prostate, colon, and breast cancer cells. J BUON 18(2):504-510

PubMed Google Scholar

156. Scarpari M, Parroni A, Zaccaria M, Fattorini L, Bello C, Fabbri AA, Bianchi G, Scala SV, Zjalic S, Fanelli C (2016) Trametes versicolor bioactive compounds stimulate Aspergillus flavus antioxidant system and inhibit aflatoxin synthesis. Plant Biosyst 150:653-659

Article Google Scholar

157. Schwartz B, Hadar $Y$ (2014) Possible mechanisms of action of mushroom-derived glucans on inflammatory bowel disease and associated cancer. Ann Transl Med 2(2):19. https://doi.org/10.3978/j.issn.2305-5839.2014.01.03

\section{CAS PubMed PubMed Central Article Google Scholar}

158. Sedky NK, El Gammal ZH, Wahba AE, Mosad E, Waly ZY, El-Fallal AA, Arafa RK, ElBadri N (2018) The molecular basis of cytotoxicity of $\alpha$-spinasterol from Ganoderma resinaceum: Induction of apoptosis and overexpression of p53 in breast and ovarian cancer cell lines. J Cell Biochem 119(5):3892-3902. https://doi.org/10.1002/jcb.26515

\section{CAS PubMed Article Google Scholar}

159. Shang D, Zhang J, Wen L, Li Y, Cui Q (2009) Preparation, characterization, and antiproliferative activities of the Se-containing polysaccharide SeGLP-2B-1 from Se-enriched Ganoderma lucidum. J Agric Food Chem 57(17):7737-7742. https://doi.org/10.1021/jf9019344

CAS PubMed Article Google Scholar

160. Shang D, Li Y, Wang C, Wang X, Yu Z, Fu X (2011) A novel polysaccharide from Seenriched Ganoderma lucidum induces apoptosis of human breast cancer cells. Oncol Rep 25(1):267-272

\section{CAS PubMed Google Scholar}

161. Shi X, Zhao Y, Jiao Y, Shi T, Yang X (2013) ROS-dependent mitochondria molecular mechanisms underlying antitumor activity of Pleurotus abalonus acidic polysaccharides in human breast cancer MCF-7 cells. PLoS One 8(5):e64266. https://doi.org/10.1371/journal.pone.0064266 
162. Shin A, Kim J, Lim SY, Kim G, Sung MK, Lee ES, Ro J (2010) Dietary mushroom intake and the risk of breast cancer based on hormone receptor status. Nutr Cancer 62(4):476-483. https://doi.org/10.1080/01635580903441212

PubMed Article Google Scholar

163. Shomali N, Onar O, Karaca B, Demirtas N, Cihan AC, Akata I, Yildirim O (2019) Antioxidant, anticancer, antimicrobial, and antibiofilm properties of the culinary-medicinal fairy ring mushroom, Marasmius oreades (Agaricomycetes). Int J Med Mushrooms 21(6):571-582. https://doi.org/10.1615/IntJMedMushrooms.2019030874

PubMed Article Google Scholar

164. Sliva D, Labarrere C, Slivova V, Sedlak M, Lloyd FP Jr, Ho NW (2002) Ganoderma lucidum suppresses motility of highly invasive breast and prostate cancer cells. Biochem Biophys Res Commun 298(4):603-612. https://doi.org/10.1016/s0006-291x(02)02496-8

CAS PubMed Article Google Scholar

165. Smina TP, Nitha B, Devasagayam TP, Janardhanan KK (2017) Ganoderma lucidum total triterpenes induce apoptosis in MCF-7 cells and attenuate DMBA induced mammary and skin carcinomas in experimental animals. Mutat Res 813:45-51. https://doi.org/10.1016/j.mrgentox.2016.11.010

CAS PubMed Article Google Scholar

166. Soares R, Meireles M, Rocha A, Pirraco A, Obiol D, Alonso E, Joos G, Balogh G (2011) Maitake (D Fraction) mushroom extract induces apoptosis in breast cancer cells by BAK-1 gene activation. J Med Food 14(6):563-572. https://doi.org/10.1089/jmf.2010.0095

CAS PubMed Article Google Scholar

167. Song X, Li Y, Zhang H, Yang Q (2015) The anticancer effect of Huaier (review). Oncol Rep 34(1):12-21. https://doi.org/10.3892/or.2015.3950

CAS PubMed Article Google Scholar

168. Song J, Wang Y, Teng M, Zhang S, Yin M, Lu J, Liu Y, Lee RJ, Wang D, Teng L (2016) Cordyceps militaris induces tumor cell death via the caspase-dependent mitochondrial pathway in HepG2 and MCF-7 cells. Mol Med Rep 13(6):5132-5140. https://doi.org/10.3892/mmr.2016.5175

CAS PubMed PubMed Central Article Google Scholar

169. Su J, Li D, Chen Q, Li M, Su L, Luo T, Liang D, Lai G, Shuai O, Jiao C, Wu Q, Xie Y, Zhou X (2018) Anti-breast cancer enhancement of a polysaccharide from spore of Ganoderma lucidum with paclitaxel: suppression on tumor metabolism with gut microbiota reshaping. Front Microbiol 9:3099. https://doi.org/10.3389/fmicb.2018.03099

PubMed PubMed Central Article Google Scholar

170. Suárez-Arroyo IJ, Rios-Fuller TJ, Feliz-Mosquea YR, Lacourt-Ventura M, Leal-Alviarez DJ, Maldonado-Martinez G, Cubano LA, Martínez-Montemayor MM (2016) Ganoderma lucidum combined with the EGFR tyrosine kinase inhibitor, Erlotinib synergize to reduce inflammatory breast cancer progression. J Cancer 7(5):500-511. https://doi.org/10.7150/jca.13599

CAS PubMed PubMed Central Article Google Scholar 
171. Sun J, Chen QJ, Cao QQ, Wu YY, Xu LJ, Zhu MJ, Ng TB, Wang HX, Zhang GQ (2012) A laccase with antiproliferative and HIV-I reverse transcriptase inhibitory activities from the mycorrhizal fungus Agaricus placomyces. J Biomed Biotechnol 2012:736472. https://doi.org/10.1155/2012/736472

\section{CAS PubMed PubMed Central Article Google Scholar}

172. Sun X, Sun Y, Zhang Q, Zhang H, Yang B, Wang Z, Zhu W, Li B, Wang Q, Kuang H (2014) Screening and comparison of antioxidant activities of polysaccharides from Coriolus versicolor. Int J Biol Macromol 69:12-19. https://doi.org/10.1016/j.ijbiomac.2014.05.027

\section{CAS PubMed Article Google Scholar}

173. Sun Y, Hu X, Li W (2017) Antioxidant, antitumor and immunostimulatory activities of the polypeptide from Pleurotus eryngii mycelium. Int $\mathrm{J}$ Biol Macromol 97:323-330. https://doi.org/10.1016/j.ijbiomac.2017.01.043

174. Suprasert P, Apichartpiyakul C, Sakonwasun C, Nitisuwanraksa P, Phuackchantuck R (2014) Clinical characteristics of gynecologic cancer patients who respond to salvage treatment with Lingzhi. Asian Pac J Cancer Prev 15(10):4193-4196

175. Suzuki N, Takimoto Y, Suzuki R, Arai T, Uebaba K, Nakai M, Strong JM, Tokuda H (2013) Efficacy of oral administration of Lentinula eododes mycelia extract for breast cancer patients undergoing postoperative hormone therapy. Asian Pac J Cancer Prev 14(6):3469 3472. https://doi.org/10.7314/apjcp.2013.14.6.3469

PubMed Article Google Scholar

176. Taguchi T (1983) Effects of lentinan in advanced or recurrent cases of gastric, colorectal, and breast cancer. Gan To Kagaku Ryoho 10(2 Pt 2):387-393

\section{CAS PubMed Google Scholar}

177. Toi M, Hattori T, Akagi M, Inokuchi K, Orita K, Sugimachi K, Dohi K, Nomura Y, Monden Y, Hamada Y, Morimoto T, Ogawa N (1992) Randomized adjuvant trial to evaluate the addition of tamoxifen and PSK to chemotherapy in patients with primary breast cancer. 5-year results from the Nishi-Nippon Group of the Adjuvant Chemoendocrine Therapy for Breast Cancer Organization. Cancer. 70(10):2475-2483. https://doi.org/10.1002/10970142(19921115)70:10<2475::aid-cncr2820701014>3.0.co;2-p

\section{CAS PubMed Article Google Scholar}

178. Trovato Salinaro A, Pennisi M, Di Paola R, Scuto M, Crupi R, Cambria MT, Ontario ML, Tomasello M, Uva M, Maiolino L, Calabrese EJ, Cuzzocrea S, Calabrese V (2018) Neuroinflammation and neurohormesis in the pathogenesis of Alzheimer's disease and Alzheimer-linked pathologies: modulation by nutritional mushrooms. Immun Ageing 15:8. https://doi.org/10.1186/s12979-017-0108-1

\section{CAS PubMed PubMed Central Article Google Scholar}

179. Tsai MY, Hung YC, Chen YH, Chen YH, Huang YC, Kao CW, Su YL, Chiu HH, Rau KM (2016) A preliminary randomised controlled study of short-term Antrodia cinnamomea treatment combined with chemotherapy for patients with advanced cancer. BMC Complement Altern Med 16(1):322. https://doi.org/10.1186/s12906-016-1312-9 
180. Tsao SM, Hsu HY (2016) Fucose-containing fraction of Ling-Zhi enhances lipid raftsdependent ubiquitination of TGF $\beta$ receptor degradation and attenuates breast cancer tumorigenesis. Sci Rep 6:36563. https://doi.org/10.1038/srep36563

\section{CAS PubMed PubMed Central Article Google Scholar}

181. Valadares F, Garbi Novaes MR, Cañete R (2013) Effect of Agaricus sylvaticus supplementation on nutritional status and adverse events of chemotherapy of breast cancer: a randomized, placebo-controlled, double-blind clinical trial. Indian J Pharm 45(3):217-222. https://doi.org/10.4103/0253-7613.111894

\section{Article Google Scholar}

182. Vaz JA, Heleno SA, Martins A, Almeida GM, Vasconcelos MH, Ferreira IC (2010) Wild mushrooms Clitocybe alexandri and Lepista inversa: in vitro antioxidant activity and growth inhibition of human tumour cell lines. Food Chem Toxicol 48(10):2881-2884. https://doi.org/10.1016/j.fct.2010.07.021

CAS PubMed Article Google Scholar

183. Wan JM, SitWH, Louie JC (2008) Polysaccharopeptide enhances the anticancer activity of doxorubicin and etoposide on human breast cancer cells ZR-75-30. Int J Oncol 32(3):689-699

184. Wang J, Xu B (2019) Targeted therapeutic options and future perspectives for HER2positive breast cancer. Sig Transduct Target Ther 4:34. https://doi.org/10.1038/s41392-0190069-2

\section{Article Google Scholar}

185. Wang HX, Ng TB, Liu WK, Ooi VE, Chang ST (1996) Polysaccharide-peptide complexes from the cultured mycelia of the mushroom Coriolus versicolor and their culture medium activate mouse lymphocytes and macrophages. Int J Biochem Cell Biol 28(5):601607. https://doi.org/10.1016/1357-2725(95)00157-3

\section{CAS PubMed Article Google Scholar}

186. Wang CR, Ng TB, Li L, Fang JC, Jiang Y, Wen TY, Qiao WT, Li N, Liu F (2011) Isolation of a polysaccharide with antiproliferative, hypoglycemic, antioxidant and HIV-1 reverse transcriptase inhibitory activities from the fruiting bodies of the abalone mushroom Pleurotus abalonus. J Pharm Pharmacol 63(6):825-832. https://doi.org/10.1111/j.20427158.2011.01274.x

187. Wang D, Zhang Y, Lu J, Wang Y, Wang J, Meng Q, Lee RJ, Wang D, Teng L (2016) Cordycepin, a natural antineoplastic agent, induces apoptosis of breast cancer cells via caspase-dependent pathways. Nat Prod Commun 11(1):63-68

PubMed Google Scholar

188. Wang KL, Lu ZM, Mao X, Chen L, Gong JS, Ren Y, Geng Y, Li H, Xu HY, Xu GH, Shi JS, Xu ZH (2019) Structural characterization and anti-alcoholic liver injury activity of a polysaccharide from Coriolus versicolor mycelia. Int J Biol Macromol 137:102-1111. https://doi.org/10.1016/j.ijbiomac.2019.06.242

CAS Article Google Scholar 
189. Wong JH, Wang HX, Ng TB (2008) Marmorin, a new ribosome inactivating protein with antiproliferative and HIV-1 reverse transcriptase inhibitory activities from the mushroom Hypsizigus marmoreus. Appl Microbiol Biotechnol 81(4):669-674. https://doi.org/10.1007/s00253-008-1639-3

190. Wong JH, Ng TB, Wang H, Sze SC, Zhang KY, Li Q, Lu X (2011) Cordymin, an antifungal peptide from the medicinal fungus Cordyceps militaris. Phytomedicine 18(5):387392. https://doi.org/10.1016/ j.phymed.2010.07.010

191. Wong JH, Sze SCW, Ng TB, Cheung RCF, Tam C, Zhang KY, Dan X, Chan YS, Shing Cho WC, Ng CCW, Waye MMY, Liang W, Zhang J, Yang J, Ye X, Lin J, Ye X, Wang H, Liu F, Chan DW, Ngan HYS, Sha O, Li G, Tse R, Tse TF, Chan H (2018) Apoptosis and anti-cancer drug discovery: the power of medicinal fungi and plants. Curr Med Chem 25(40):5613-5630. https://doi.org/10.2174/0929867324666170720165005

192. Wu L, Wu Z, Lin Q, Xie L (2003) Purification and activities of an alkaline protein from mushroom Coprinus comatus. Wei Sheng Wu Xue Bao 43(6):793-798

CAS PubMed Google Scholar

193. Wu JY, Zhang QX, Leung PH (2007) Inhibitory effects of ethyl acetate extract of Cordyceps sinensis mycelium on various cancer cells in culture and B16 melanomain C57BL/6 mice. Phytomedicine. 14(1):43-49. https://doi.org/10.1016/j.phymed.2005.11.005

\section{CAS PubMed Article Google Scholar}

194. Wu G, Qian Z, Guo J, Hu D, Bao J, Xie J, Xu W, Lu J, Chen X, Wang Y (2012a) Ganoderma lucidum extract induces $\mathrm{G} 1$ cell cycle arrest, and apoptosis in human breast cancer cells. Am J Chin Med 40(3):631-642. https://doi.org/10.1142/S0192415X12500474

\section{CAS PubMed Article Google Scholar}

195. Wu GS, Lu JJ, Guo JJ, Li YB, Tan W, Dang YY, Zhong ZF, Xu ZT, Chen XP, Wang YT (2012b) Ganoderic acid DM, a natural triterpenoid, induces DNA damage, G1 cell cycle arrest and apoptosis in human breast cancer cells. Fitoterapia. 83(2):408-414. https://doi.org/10.1016/j.fitote.2011.12.004

CAS PubMed Article Google Scholar

196. Wu GS, Song YL, Yin ZQ, Guo JJ, Wang SP, Zhao WW, Chen XP, Zhang QW, Lu JJ, Wang YT (2013) Ganoderiol A-enriched extract suppresses migration and adhesion of MDAMB-231 cells by inhibiting FAK-SRC-paxillin cascade pathway. PLoS One 8(10):e76620. https://doi.org/10.1371/journal.pone.0076620

CAS PubMed PubMed Central Article Google Scholar

197. Xu DP, Zheng J, Zhou Y, Li Y, Li S, Li HB (2016a) Extraction of natural antioxidants from the Thelephora ganbajun mushroom by an ultrasound-assisted extraction technique and evaluation of antiproliferative activity of the extract against human cancer cells. Int J Mol Sci 17(10):E1664. https://doi.org/10.3390/ijms17101664

CAS PubMed Article Google Scholar

198. Xu H, Kong YY, Chen X, Guo MY, Bai XH, Lu YJ, Li W, Zhou XW (2016b) Recombinant FIP-gat, a fungal immunomodulatory protein from Ganoderma atrum, induces growth inhibition and cell death in breast cancer cells. J Agric Food Chem 64(13):2690-2698. https://doi.org/10.1021/acs.jafc.6b00539 
199. Xu H, Zou S, Xu X (2017) The $\beta$-glucan from Lentinus edodes suppresses cell proliferation and promotes apoptosis in estrogen receptor positive breast cancers. Oncotarget 8(49):86693-86709. https://doi.org/10.18632/oncotarget.21411

\section{PubMed PubMed Central Article Google Scholar}

200. Xue Z, Li J, Cheng A, Yu W, Zhang Z, Kou X, Zhou F (2015) Structure identification of triterpene from the mushroom Pleurotus eryngii with inhibitory effects against breast cancer. Plant Foods Hum Nutr 70(3):291-296. https://doi.org/10.1007/s11130-015-0492-7

201. Yamaguchi Y, Miyahara E, Hihara J. Efficacy and safety Yamaguchi Y, Miyahara E, Hihara J (2011) Efficacy and safety of orally administered Lentinula edodes mycelia extract for patients undergoing cancer chemotherapy: a pilot study. Am J patients undergoing cancer chemotherapy: a pilot study. Am J Chin Med 39(3):451-459. https://doi.org/10.1142/S0192415X1100895610.1142/S0192415X11008956

202. Yang HL, Kuo YH, Tsai CT, Huang YT, Chen SC, Chang HW, Lin E, Lin WH, Hseu YC (2011) Anti-metastatic activities of Antrodia camphorata against human breast cancer cells mediated through suppression of the MAPK signaling pathway. Food Chem Toxicol 49(1):290298. https://doi.org/10.1016/j.fct.2010.10.031

CAS PubMed Article Google Scholar

203. Yang Q, Yin Y, Yu G, Jin Y, Ye X, Shrestha A, Liu W, Yu W, Sun H (2015) A novel protein with anti-metastasis activity on 4T1 carcinoma from medicinal fungus Cordyceps militaris. Int J Biol Macromol 80:385-391. https://doi.org/10.1016/j.ijbiomac.2015.06.050

204. Yang Y, Zhou H, Liu W, Wu J, Yue X, Wang J, Quan L, Liu H, Guo L, Wang Z, Lian X, Zhang Q (2018) Ganoderic acid A exerts antitumor activity against MDA-MB-231 human breast cancer cells by inhibiting the Janus kinase 2/signal transducer and activator of transcription 3 signaling pathway. Oncol Lett 16(5):6515-6521. https://doi.org/10.3892/ol.2018.9475

\section{CAS PubMed PubMed Central Article Google Scholar}

205. Yap HY, Fung SY, Ng ST, Tan CS, Tan NH (2015) Shotgun proteomic analysis of tiger milk mushroom (Lignosus rhinocerotis) and the isolation of a cytotoxic fungal serine protease from its sclerotium. J Ethnopharmacol 174:437-451. https://doi.org/10.1016/j.jep.2015.08.042

206. Yap HY, Muria-Gonzalez MJ, Kong BH, Stubbs KA, Tan CS, Ng ST, Tan NH, Solomon PS, Fung SY, Chooi YH (2017) Heterologous expression of cytotoxic sesquiterpenoids from the medicinal mushroom Lignosus rhinocerotis in yeast. Microb Cell Fact 16(1):103. https://doi.org/10.1186/s12934-017-0713-x

207. Yap HYY, Tan NH, Ng ST, Tan CS, Fung SY (2018) Molecular attributes and apoptosisinducing activities of a putative serine protease isolated from Tiger Milk mushroom (Lignosus rhinocerus) sclerotium against breast cancer cells in vitro. PeerJ. 6:e4940. https://doi.org/10.7717/peerj.4940

CAS PubMed PubMed Central Article Google Scholar

208. Yeung JH, Or PM (2011) Polysaccharide peptides from Coriolus versicolor competitively inhibit tolbutamide 4-hydroxylation in specific human CYP2C9 isoform and pooled human liver microsomes. Phytomedicine 18(13):1170-1175. https://doi.org/10.1016/j.phymed.2011.06.002 
209. Yeung JH, Or PM (2012) Polysaccharide peptides from Coriolus versicolor competitively inhibit model cytochrome P450 enzyme probe substrates metabolism in human $\begin{array}{lll}\text { liver microsomes. } & \text { Phytomedicine. }\end{array}$ https://doi.org/10.1016/j.phymed.2011.09.077

CAS PubMed Article Google Scholar

210. Yi C, Fu M, Cao X, Tong S, Zheng Q, Firempong CK, Jiang X, Xu X, Yu J (2013a) Enhanced oral bioavailability and tissue distribution of a new potential anticancer agent, Flammulina velutipes sterols, through liposomal encapsulation. J Agric Food Chem 61(25):5961-5971. https://doi.org/10.1021/jf3055278

CAS PubMed Article Google Scholar

211. Yi C, Sun C, Tong S, Cao X, Feng Y, Firempong CK, Jiang X, Xu X, Yu J (2013b) Cytotoxic effect of novel Flammulina velutipes sterols and its oral bioavailability via mixed micellar nanoformulation. Int $J$ Pharm 448(1):44-50. https://doi.org/10.1016/j.ijpharm.2013.03.020

\section{CAS PubMed Article Google Scholar}

212. Zaidman BZ, Wasser SP, Nevo E, Mahajna J (2008) Coprinus comatus and Ganoderma lucidum interfere with androgen receptor function in LNCaP prostate cancer cells. Mol Biol Rep 35(2):107-117. https://doi.org/10.1007/s11033-007-9059-5

CAS PubMed Article Google Scholar

213. Zhang Y (2017) Ganoderma lucidum (Reishi) suppresses proliferation and migration of breast cancer cells via inhibiting Wnt/ $\beta$-catenin signaling. Biochem Biophys Res Commun 488(4):679-684. https://doi.org/10.1016/j.bbrc.2017.04.086

CAS PubMed Article Google Scholar

214. Zhang M, Chiu LC, Cheung PC, Ooi VE (2006) Growth-inhibitory effects of a betaglucan from the mycelium of Poria cocos on human breast carcinoma MCF-7 cells: cell-cycle arrest and apoptosis induction. Oncol Rep 15(3):637-643

PubMed Google Scholar

215. Zhang GQ, Sun J, Wang HX, Ng TB (2009a) A novel lectin with antiproliferative activity from the medicinal mushroom Pholiota adiposa. Acta Biochim Pol 56(3):415-421

CAS PubMed Article Google Scholar

216. Zhang M, Huang J, Xie X, Holman CD, Arcy J (2009b) Dietary intakes of mushrooms and green tea combine to reduce the risk of breast cancer in Chinese women. Int $\mathrm{J}$ Cancer 124(6):1404-1408

CAS PubMed Article Google Scholar

217. Zhang G, Sun J, Wang H, Ng TB (2010a) First isolation and characterization of a novel lectin with potent antitumor activity from a Russula mushroom. Phytomedicine. 17(10):775781. https://doi.org/10.1016/j.phymed.2010.02.001

CAS PubMed Article Google Scholar 
218. Zhang RY, Zhang GQ, Hu DD, Wang HX, Ng TB (2010b) A novel ribonuclease with antiproliferative activity from fresh fruiting bodies of the edible mushroom Lyophyllum shimeiji. Biochem Genet 48(7-8):658-668. https://doi.org/10.1007/s10528-010-9347-y

CAS PubMed Article Google Scholar

219. Zhang M, Zhu L, Cui SW, Wang Q, Zhou T, Shen H (2011) Fractionation, partial characterization and bioactivity of water-soluble polysaccharides and polysaccharide-protein complexes from Pleurotus geesteranus. Int $J$ Biol Macromol 48(1):5-12. https://doi.org/10.1016/j.jibiomac.2010.09.003

CAS PubMed Article Google Scholar

220. Zhang Y, Liu Z, Ng TB, Chen Z, Qiao W, Liu F (2014) Purification and characterization of a novel antitumor protein with antioxidant and deoxyribonuclease activity from edible mushroom Pholiota nameko. Biochimie 99:28-37. https://doi.org/10.1016/j.biochi.2013.10.016

CAS PubMed Article Google Scholar

221. Zhang L, Khoo CS, Koyyalamudi SR, de Pedro N, Reddy N (2017a) Antioxidant, antiinflammatory and anticancer activities of ethanol soluble organics from water extracts of selected medicinal herbs and their relation with flavonoid and phenolic contents. Pharmacologia 8:59-72. https://doi.org/10.5567/pharmacologia.2017.59.72

\section{CAS Article Google Scholar}

222. Zhang P, Li K, Yang G, Xia C, Polston JE, Li G, Li S, Lin Z, Yang LJ, Bruner SD, Ding $Y(2017 b)$ Cytotoxic protein from the mushroom Coprinus comatus possesses a unique mode for glycan binding and specificity. Proc Natl Acad Sci U S A 114(34):8980-8985. https://doi.org/10.1073/pnas.1706894114

CAS PubMed PubMed Central Article Google Scholar

223. Zhang M, Zhang Y, Zhang L, Tian Q (2019a) Mushroom polysaccharide lentinan for treating different types of cancers: a review of 12 years clinical studies in China. Prog Mol Biol Transl Sci 163:297-328. https://doi.org/10.1016/bs.pmbts.2019.02.013

CAS PubMed Article Google Scholar

224. Zhang $Y$, Jiang $Y$, Zhang M, Zhang L (2019b) Ganoderma sinense polysaccharide: An adjunctive drug used for cancer treatment. Prog Mol Biol Transl Sci 163:165-177. https://doi.org/10.1016/bs.pmbts.2019.02.008

CAS PubMed Article Google Scholar

225. Zhao S, Zhao Y, Li S, Zhao J, Zhang G, Wang H, Ng TB (2010) A novel lectin with highly potent antiproliferative and HIV-1 reverse transcriptase inhibitory activities from the edible wild mushroom Russula delica. Glycoconj J 27(2):259-265. https://doi.org/10.1007/s10719-009-9274-5

CAS PubMed Article Google Scholar

226. Zhong K, Tong L, Liu L, Zhou X, Liu X, Zhang Q, Zhou S (2015) Immunoregulatory and antitumor activity of schizophyllan under ultrasonic treatment. Int J Biol Macromol 80:302-308. https://doi.org/10.1016/j.jibiomac.2015.06.052

CAS PubMed Article Google Scholar 
227. Zhou DH, Lin LZ (1995) Effect of Jinshuibao capsule on the immunological function of 36 patients with advanced cancer. Zhongguo Zhong Xi Yi Jie He Za Zhi 15(8):476-478

228. Zhu-Salzman K, Hammen PK, Salzman RA, Hisashi Koiwa RA, Bressan L, Murdock L, Hasegawa PM (2002) Calcium modulates protease resistance and carbohydrate binding of a plant defense legume lectin, Griffonia simplicifolia lectin II (GSII). Comp Biochem Physiol B: Biochem Mol Biol 132(2):327-334

Article Google Scholar

229. Zurrida S, Veronesi U (2015) Milestones in breast cancer treatment. Breast J 21(1):3. https://doi.org/10.1111/tbj.12361

CAS PubMed Article Google Scholar

Download references

Acknowledgments

We gratefully acknowledge the award of HMRF research grant (No. 12131221) from the Food and Health Bureau, the Government of Hong Kong Special Administrative Region, and a grant from the National Natural Science Foundation of China (No. 81471927). We are thankful for support of the science and technology project of the Science and Technology Innovation Commission of Shenzhen (No. JCYJ20170818094217688) and the discipline construction project of biochemistry and molecular biology from the National Development and Reform Commission (85629-000001 and 1452).

Author information

Ethics declarations

Ethical statement

This work does not contain any studies with human participants or animals performed by any of the authors.

Conflict of interest

The authors declare that they have no conflict of interest. 